\title{
Crystal Growth in Gels from the Mechanisms of Crystal Growth to Control of Polymorphism: New Trends on Theoretical and Experimental Aspects
}

\author{
Omar Velásquez-González ${ }^{1,2}$, Camila Campos-Escamilla ${ }^{2}$, Andrea Flores-Ibarra ${ }^{2}$, \\ Nuria Esturau-Escofet ${ }^{2}$ D , Roberto Arreguin-Espinosa ${ }^{2}$, Vivian Stojanoff ${ }^{3}$, \\ Mayra Cuéllar-Cruz ${ }^{2,4}$ (D) and Abel Moreno ${ }^{2, *(\mathbb{D})}$ \\ 1 Escuela de Química, Universidad de San Carlos Guatemala, Ciudad de Guatemala 01012, Guatemala \\ 2 Instituto de Química, Universidad Nacional Autónoma de Mexico, Av. Universidad 3000, \\ Ciudad Universitaria, Ciudad de Mexico 04510, Mexico \\ 3 NSLS-II-Brookhaven National Laboratory, Upton, New York, NY 11973, USA \\ 4 Departamento de Biología, División de Ciencias Naturales y Exactas, Campus Guanajuato, \\ Universidad de Guanajuato, Noria Alta S/N, Col. Noria Alta, Guanajuato C. P. 36050, Guanajuato, Mexico \\ * Correspondence: carcamo@unam.mx; Tel.: +52-55-56224467
}

Received: 1 August 2019; Accepted: 23 August 2019; Published: 26 August 2019

check for updates

\begin{abstract}
A gel can be considered to be a two-phase (liquid and solid) system, which lacks flow once it reaches a stationary state. The solid phase is usually a tridimensional polymeric mesh, while the liquid phase is usually found in three forms: contained in great cavities, retained in the capillary pores between micelles, or adsorbed on the surface of a micelle. The influence of the use of gels in crystal growth is diverse and depends on the type of gel being used. A decrease in solubility of any solute in the liquid may occur if the solvent interacts extensively with the polymeric section, hence, the nucleation in gels in these cases apparently occurs at relatively low supersaturations. However, if the pore size is small enough, there is a possibility that a higher supersaturation is needed, due to the compartmentalization of solvents. Finally, this may also represent an effect in the diffusion of substances. This review is divided into three main parts; the first evaluates the theory and practice used for the obtainment of polymorphs. The second part describes the use of gels into crystallogenesis of different substances. The last part is related to the particularities of protein crystal polymorphism, as well as modern trends in gel growth for high-resolution X-ray crystallography.
\end{abstract}

Keywords: gel growth; mechanism of crystal growth; polymorphism; crystallogenesis; hydrogels

\section{Polymorphism}

\subsection{Definition}

The aim of this review is to describe how the use of gels affects the polymorphism of a crystalline substance. However, to fulfill this analysis, it is important to define the term "polymorphism" for the purposes of this review. A simple and straightforward definition could describe it as a solid-state phenomenon in which more than one crystalline form can be obtained for a single compound. This definition, however, may result ambiguous, given that a "crystalline form" could refer either to the network, to the crystal structure, or even to an allotrope. A more specific definition, then, could be the one given by Burger [1], which mentions that a solid that can exist in different crystalline networks is a polymorph. Nevertheless, there are cases where a polymorph could be a system with the same network, but with a different molecular conformation. 
A more concise way of using this term could probably emerge from the effects of polymorphism itself. At a pharmaceutical level, the presence of polymorphs of a compound causes differences in solubility and stability, and in the formulation procedures for that particular compound [2-11]. In biomineral systems, organisms use different polymorphs according to the system and function that are needed [12-14]. In structural biology, the polymorphism of a protein broadly varies in terms of its network, as well as of its conformations $[15,16]$. According to these effects, two categories have been observed. On one hand, flexible molecules may adopt a variety of conformations in the solid state, a phenomenon known as conformational polymorphism. However, if the difference is found in the crystalline structure, or the crystal network, it is known as packing polymorphism. The latter is majorly found in rigid structures.

The best definition, given that it covers the important cases previously mentioned, and that it is not too general, could be the one proposed by McCrone, who defines a polymorph as a "solid crystalline phase of a given compound that results in the possibility of at least two different arrangements of the molecules of said compound in the solid state" [17].

\subsection{Nucleation and Polymorphism}

To obtain a crystal of a certain polymorph, two consecutive events with different characteristics must occur: first, a shift from a supersaturated solution to microscopic solid nuclei, and afterwards, crystal growth from the previously formed nuclei [18]. These crystallization steps condition the structure of the solid, and therefore, are intimately linked to the final polymorphic form.

Regarding nucleation, two different theories can describe it. The first one, known as the classic nucleation theory (CNT), is based on the heterogenous separation of a phase into another, established from Gibbs's thermodynamic description [19] and formulated for this specific case by Frankel [20]. This theory indicates that the growth of the nucleus is a purely stochastic event, and that it is a competition between the increase in free energy, mainly due to an enthalpic factor of the forming nucleus's liquid-solid interphase surface, against the decrease in energy due to the formation of the solid. As illustrated in Figure 1, there is a critical radius, denoted as $\mathbf{r}^{\prime}$, over which if the number of units of the nucleus being formed necessary to reach said radius is surpassed, the decrease in the free energy due to the formation of the solid allows the nucleus to remain thermodynamically stable and keep growing [21].

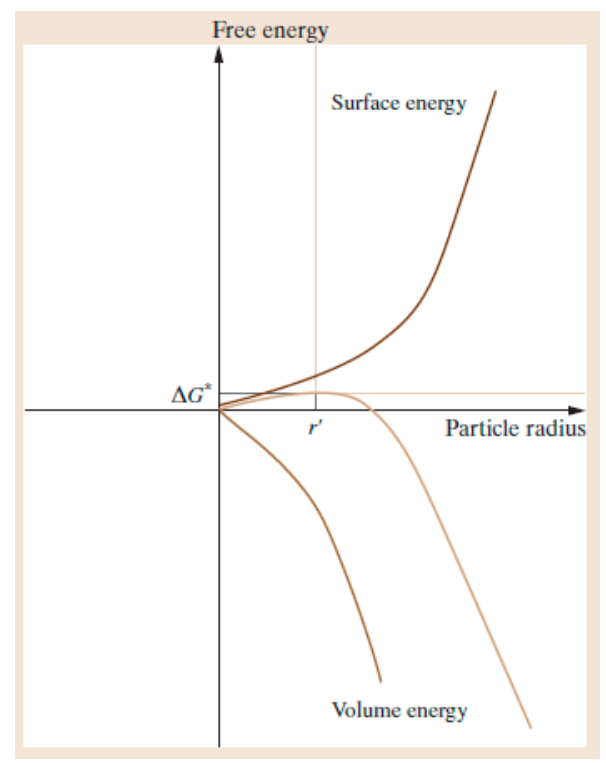

Figure 1. Free energy of the nucleation [21]. With permit of the copyright (Copyright Clearance Center License 4635650204890). Reproduced with permission from Springer Handbook of Crystal Growth; Springer: Berlin/Heidelberg, Germany, 2010. 
In principle, the structure of the nucleus may be equal to the macroscopically observed polymorph. Since nucleation is a stochastic event, the control of the formation of a specific polymorph would arise from increasing the probability of nucleus formation by handling specific conditions. The use of binary mixtures of solvents $[22,23]$ is a broadly used technique, mostly in the area of small organic molecules. Polymorphs of spironolactone can be obtained through a fine control of the solvation states [24]; a study made with isonicotinamide and 4-hydroxyacetophenone shows how to obtain different polymorphs in binary mixtures of organic solvents [25], or for the synthesis of p-aminobenzoic acid [26]. Furthermore, industrial production systems have been designed based on the continuous production of p-aminobenzoic acid [27]. An interesting variation in this two-phase system is the use of $\mathrm{CO}_{2}$ as an antisolvent, for the production of carbamazepine [28].

Several strategies have been used to increase the probability of nucleation for a specific polymorph. For instance, the design of a thermodynamic model capable of feedback by ATR-FTIR methods, for L-glutamic acid [29]; the use of mechanochemistry for the synthesis of Schiff bases [30-32]; open interchange systems [33]; temperature modifications [34]; application of pulsated laser for exerting pressure by the clash of highly coherent photons, and the modification of the local temperature $[35,36]$. Also, attempts have been made for a direct separation of the nucleation phenomenon, using seeds, for different applications [31,32,37].

It has been found that a specific polymorph can be selected by controlling the velocity of nucleation. Glycine has been a widely used model, for which an experiment was performed, evaluating the hundreds of cases where the selection between the $\alpha$ and $\gamma$ polymorphs took place through the nucleation and growth properties [38]. For several oxides and inorganic salts, this selection may be made by the adjustment of $\mathrm{pH}$, the concentration of additives, or the dissolution of non-crystalline or initially formed poorly ordered oxides [39]. The latter is known as the Oswald-Rippening effect [40], which consists of the dissolution of small crystals and their re-deposition in the dissolved species over bigger crystals [41]; this effect occurs due to the fact that smaller particles have a greater surface energy than the bigger ones [42]. The use of certain additives that modify the ionic strength could also be used as a variant for this mechanism, as exemplified by the growth of aluminum hydroxide polymorphs [43].

Even though in principle metastable phases should transition towards a thermodynamically stable phase, there are several different metastable phases at nanoscale with slight differences in the Gibbs energy and enthalpy, which could contribute to the forming of different polymorphs, as in the case of titanium oxide. Figure 2 illustrates the control of the metastability of this compound by enthalpy. In fact, the difference is so small that a slight change in the surface area causes a change in the volumetric enthalpy, which could in turn modify the order of the most favored polymorph. There is a direct influence of the surface enthalpy of the polymorph with its stability. Therefore, this is presented as a strategy that can be used, either in a laboratory or by organisms themselves, for the precipitation of the desired polymorph with a determined size distribution. In this case, the less dense phase presents a lower uncompensated charge density, due to its lower packing density. This also allows a greater molecular relaxation, decreasing the tension from bonds, torsion angles, and dihedral angles, making it a general behavior, and making amorphous or less stable precipitation a thermodynamically and kinetically preferred process. Once growth in the metastable phase is initiated, a new nucleation event is required to form the stable phase [44]. 


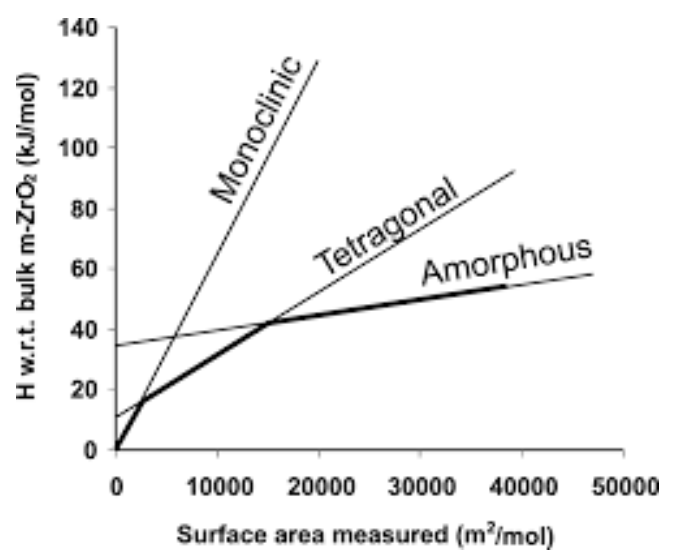

Figure 2. Volumetric energy in relation to surface area [44]. Copyright (2004) National Academy of Sciences, USA.

Additionally, the degree of supersaturation has an important effect. It has been observed that in highly saturated solutions, the pathways of nucleation can favor the formation of the metastable polymorph, while in solutions with lower concentrations different local structures are transformed in the crystal's stable phase [45].

Although the idea that the polymorph that is initially formed in the nucleus is the one that generates the final polymorph, there are cases of cross-nucleation. The existence of this kind of concomitant polymorphism has been attributed either to the competition in the process of nucleation of several polymorphs, to the conversion between polymorphs, to the solvent, or to the heterogenous nucleation of a polymorph onto another. It seems to take place when two polymorphs have very similar free energies and thus the effects of selection become explicitly dependent on the kinetics, most of all in the case of crystallization of supercooled liquids [46,47]. In this type of systems, the existence of a shared crystallographic plane appears to importantly serve as an interphase [48].

On another scheme, outside of the classic nucleation theory, the existence of a multi-stage nucleation has been proposed. In this case, the first step is the formation of a dense liquid drop, metastable with respect to the crystalline state, followed by the formation of a crystal from said drop [49]. The structural fluctuation overrules the density fluctuation, obtaining a favored crystalline structure through an auto-assembling system [50].

An interesting study regarding this nucleation mechanism is the one made by Gebauer, Völkel, and Cölfen. It demonstrates that dissolved calcium carbonate, in fact, contains metastable ionic clusters, even in non-saturated solutions, which makes us think that the formation of nuclei is not completely stochastic and, in this case, it can be treated as an equilibrium issue (see Figure 3). These mechanisms are also important in the crystallization of other minerals. The amount of free calcium detected by an ion-selective electrode increases in a much slower manner than the amount of calcium that is added from the beginning of the experiment, in saturated systems as well as in unsaturated systems, indicating a minimum in the Gibbs free energy (see Figure 4). 


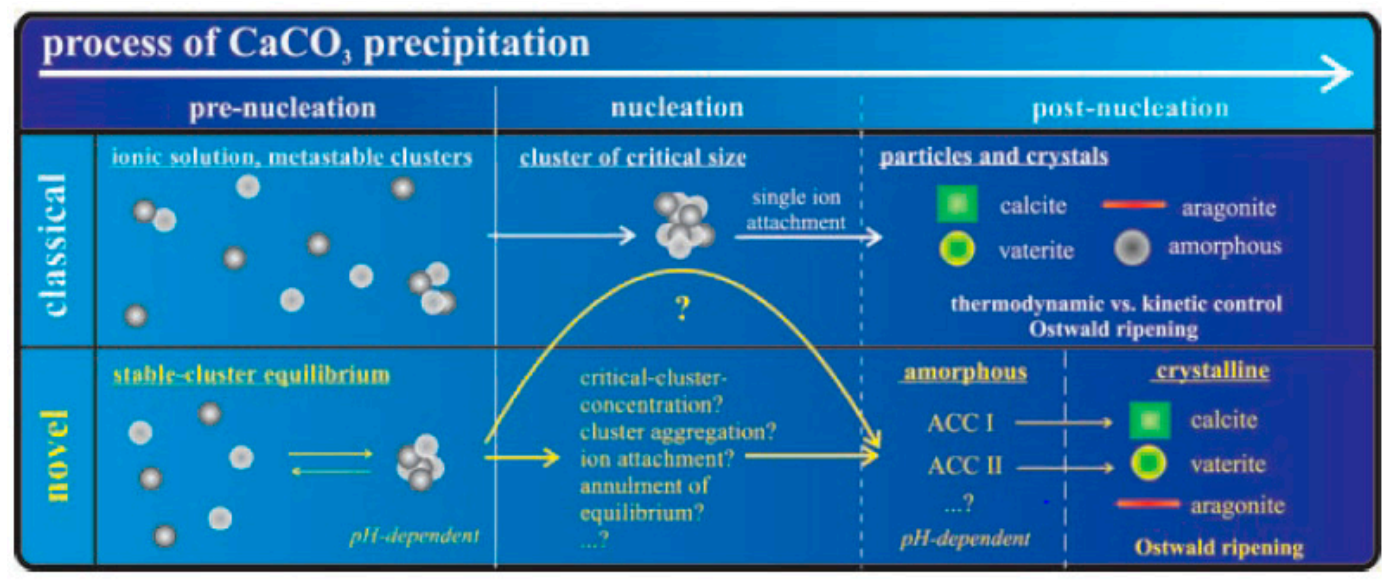

Figure 3. Calcium carbonate precipitation mechanism [51]. With permit of the copyright (Copyright Clearance Center License 4635610839441).

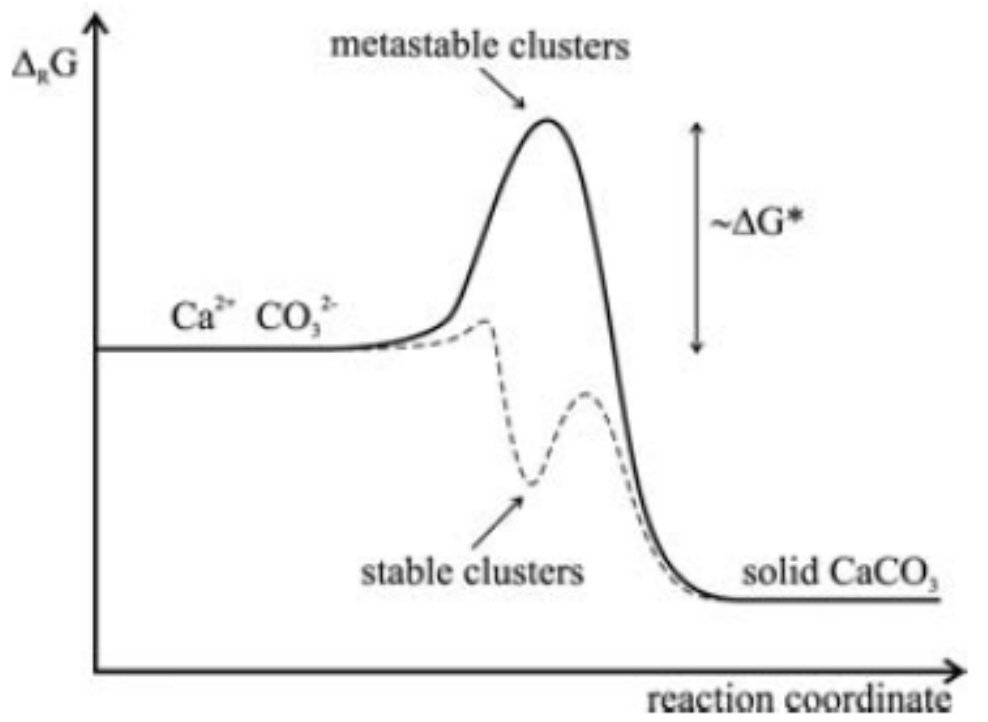

Figure 4. Comparative scheme of the Gibbs free energy between CNT and cluster formation [51]. With permit of the copyright (Copyright Clearance Center License 4635610839441).

In the pre-nucleation stage, the cluster apparently exhibits a "solute character", meaning that there is no surface tension inherent to the phase shifts and limits, but there are effects in the hydration energy. The surface tension that characterizes the interphase is established when the critical stage is reached, and the amorphous form is precipitated [51].

A combination of a liquid metastable prior-to-nucleation system and the use of solvents, as explained at the beginning of this section, is the proposal for pyraclostrobin, using isopropanol/cyclohexane and characterizing the oiling out points for the different mixtures [52]. This behavior has been observed in proteins; Muschol made an oiling out point analysis for the separation of hen white-egg lysozyme solutions, where pre-nucleation clusters are observed. Evaluation of other proteins with different characteristics suggests that this behavior is common in globular proteins [53].

The possibility of thermodynamically stable clusters opens the door to the existence of a polymorphic control guided at molecular level. In the pharmaceutical area, the auto-assembly of dimers of tolfenamic acid (a non-steroidal anti-inflammatory drug) has been detected and used; this way, the dimers act as a template for the cluster [54]. Also, the secondary structure of peptides in general may have an influence in the kinetic and thermodynamic control for the cluster's auto-assembly, and thus permit a structural polymorphic control [55]. 
The use of auxiliary additives has been published for several compounds, being paradigmatic examples the use of malonic acid in the synthesis of the glycine $\gamma$ polymorph crystal, and the use of surfactants in inorganic compounds [56]. A further step is the use of custom-made molecular auxiliaries for obtaining configurationally blocked polyenes, with the nucleation of a non-centrosymmetric polymorph [57].

The versatility of an auto-assembly molecular focus has been shown by different groups in different areas. Henceforth, the use of macromolecules extracted from natural sources to induce the polymorph of the biomineral in which they were found is widely reported [12]. In fact, the isolation of several proteins with a high content of acidic amino acids, involved in biomineralization of calcium carbonate in aviary eggshells, has been accomplished [58-60], as well as the precipitation of aragonite in fish otolith [13] in the organic matrix of corals. The influence of these amino acids is possibly due to the stabilization of the plane with a more positive charge by the anions of the side chain, such as the case of vaterite [61]. This effect has given place to the synthesis of materials that emulate biomolecules, such as poly-aspartic acid chains [62].

Small supramolecular systems imitate the protein-assisted auto-assembly behavior, allowing the generation of specific polymorphs that can be used as molecular templates. The use of silver nanoparticles permits obtaining a single piezoelectric polymorph of a vynilfluoride polymer [63], whereas gold auto-assembled hydrophilic islands drive the nucleation of glycine polymorphs [64]. Cyclodextrins have been used to form inclusion complexes with a group of polymers, given that, by being appropriately removed, the host is forced to coalesce into a pure polymeric solid, favoring the polymorph whose structure is the most extended [65]. In the same way, using monolayers of amphiphilic calixarenes favors the formation of specific polymorphs of gabapentin [66]. An interesting application is the design of an organic semiconductor, consisting of a polymorph and a nanoprinted polyimide layer [67].

\section{Gels}

\subsection{Properties of Gels Used for Crystallization}

A gel can be considered to be a two-phase (liquid and solid) system, which lacks flow once it reaches a stationary state [68]. The solid phase is usually a tridimensional polymeric mesh, while the liquid phase is usually found in three forms: contained in great cavities, retained in the capillary pores between micelles, or adsorbed on the surface of a micelle. The vicinal water to the solid phase is structured in a different manner than the bulk liquid phase; it can extend from tens to thousands of molecular diameters. Then, a semi-structured structure may be found, which finally conducts to the aqueous bulk water phase per se. The influence of the use of gels in crystalline polymorphism is diverse and depends on the type of gel being used. A decrease in solubility of any solute in the liquid may occur if the solvent interacts extensively with the polymeric section, hence, the nucleation in gels in these cases apparently occurs at relatively low supersaturations. However, if the pore size is small enough, there is a possibility that a higher supersaturation is needed, due to the compartmentalization of solvents. Finally, this may also represent an effect in the diffusion of substances [69-71].

For the solid phase, the micellar theory may be used to describe "physical" gels. This theory models the gel as consisting of small droplets of liquid held by a solid cellular structure. This type of structure is favorable in the cases of dissolved polymers with asymmetric molecular units and voluminous side groups. For "chemical" gels, the fibrillar theory best describes their nature. In this case, the solid forms a continual fibrous structure that contains the liquid inside its pores. This property exhibits a considerable loss in thixotropy, making the rupture of the bonds difficult, but also lacking re-structuration once it is modified. These gels have a high degree of elasticity. Two types of capillary channels have been observed: "secondary" channels, which obey capillary theory, and "primary" channels, close to molecular dimensions [72]. This can be observed in Figure 5, which presents the 
cases of gels synthesized from agarose and furcellaran, and how the size of the capillary channels may influence polymorphism [73].
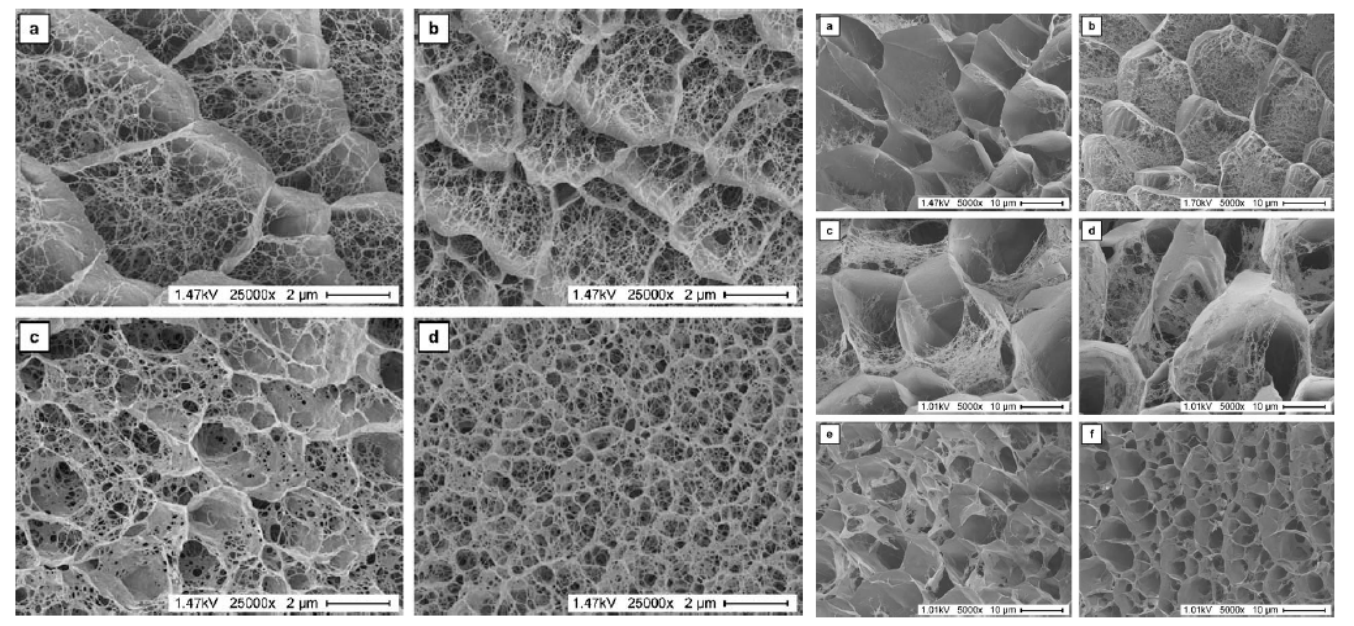

Figure 5. Agarose and furcellaran gels ultrastructure [73]. The image on the left: SEM images of $2 \%$ agarose network structures at a) $70^{\circ} \mathrm{C}$, b) $40{ }^{\circ} \mathrm{C}$, c) $30^{\circ} \mathrm{C}$ and d) $20^{\circ} \mathrm{C}$. The image on the right: SEM images of $2 \%$ furcellaran network structures at a) $\left.\left.70^{\circ} \mathrm{C}, \mathbf{b}\right) 50^{\circ} \mathrm{C}, \mathbf{c}\right) 40^{\circ} \mathrm{C}$, d) $\left.35^{\circ} \mathrm{C}, \mathbf{e}\right) 30^{\circ} \mathrm{C}$ and f) $20^{\circ} \mathrm{C}$. With permit of the copyright (Copyright Clearance Center License 4635620542204).

Gels that are good candidates for crystal growth have a continuous structure in the solid phase as well as in the liquid phase, and they have a sufficient degree of elasticity and mechanical yield to allow the crystal to grow. The effect of the structure in the liquid phase is influenced by the proximity to the gel and the content of electrolytes [74].

For crystallization purposes, the use of hydrogels is widely used. The solid phase has not a rigid skeleton but a cross-linked structure. The gel formation process can be monitored through nephelometry. The intensity increases until it reaches a plateau, during the time it takes for gel to form. Contrary to what happens in a solution, where crystals are deposited, in a gel the crystals are suspended in the polymeric network. Nevertheless, since it is not a rigid structure, the developing crystal is able to push the gel as it grows.

An important difference in contrast to a solution system is that in a solution, the depletion of the substrate from the crystal generates convective currents due to the density change by the loss of solute; however, convection is eliminated in a gel, and thus the mass transport is merely diffusive. This happens most of all in cases where the molecule size is considerably less than the gel's (for molecules with similar dimensions, diffusion may be decreased or stopped altogether).

Nucleation has been observed to be reduced in a gel, especially if it is a silica gel, for two reasons: first, secondary nucleation is practically depleted because it normally occurs due either to collisions between growing nuclei or to the diminution of the liquid's flow; second, heterogenous nucleation, due to chemical species other than the crystal, is eliminated by the filtrating property of the gel's polymeric network and by the high supersaturation in the gel compartments (heterogenous nucleation usually occurs at low saturation levels) [75].

If a crystallization system follows a diffusive regime, as in the case of gels, then the crystal growth dynamics can be explained by Fick's laws. A two-compartment system containing two species that mixed together form an insoluble specie can be used as a base model. If both compartments are contiguous, the species inside them mix rapidly with a high rate of supersaturation. However, if the compartments are not contiguous but are separated by an intermediate mixing compartment, a concentration gradient is generated along this compartment, depending on the transport kinetics. Since kinetics is controlled by a slow transport, the best strategy to diminish the velocity of the system's mass transport is to restrict mass transport to a diffusion column and to avoid convection. 
The concentration in the column will vary according to Fick's diffusion law. The analytic solution will assume an initial microscopic gradient, which is not realistic as the gel's column is semi-infinite, since in real experiments the concentrations of the reactants in the reservoirs vary with time. A precipitation criterium is necessary to evaluate the formation of the solid when thermodynamic equilibrium is reached. The product of thermodynamic solubility may be used establishing a precipitation region, which includes its metastable range. Nevertheless, when the ratio between both reactants is far from stoichiometry (which is something common in crystalline growth), the nucleation kinetics invalids the use of the product of solubility.

A limit system may be evaluated, in which one of the compounds that form the crystal is in a proportion greater than the Kps value, which is low enough so that the amount of substance is less than the one required for the formation of the critic nucleus. In the case of a supersaturated system, and according to the nucleation theory, the velocity of nucleation is a function of the number of collisions between atoms " $\mathrm{A}$ " and " $\mathrm{B}$ ". The probability is given by an exponential unimodal distribution with a maximum of $\frac{1}{2}$. Therefore, if the ratio between the solutions is not equivalent, nucleation is decreased [76-78].

\subsection{Studies on Crystal Growth in Gels}

The use of gels to obtain solid structures has been known since the interwar period, with the well-known Liesegang rings [79], and it has been broadly documented mostly for obtaining monocrystals available for the tridimensional elucidation of structures.

In one of his first works, Henisch [80] obtained calcium tartrate in silica gels, and the specific characteristics of the gel were observed in the obtained crystal, as an attempt to explain the growth of bigger crystals, in this case. These crystals may be used for macroseeding. In general, the number of formed crystals is proportional to the distance of the gel's interphase, usually in an exponential manner. The calculations for diffusion relations are very close to the models for heat conduction in a bar; instead of losing heat, the gel system "loses" calcium ions due to the bonding with tartrate ions in the solution [80].

McCaurey and Roy performed an experiment in which they synthesized calcium carbonate polymorphs using silica gel [81], which was later further developed by performing the experiments at different temperatures. Since aragonite is a metastable form, its formation depends on the kinetics of nucleus formation. In a gel-controlled diffusion regime growth experiment, a fast differential precipitation occurs at temperatures over $50{ }^{\circ} \mathrm{C}$, with a maximum at $200^{\circ} \mathrm{C}$. At $270{ }^{\circ} \mathrm{C}$, only calcite is formed, since the high temperature matches the diffusion velocity of both polymorphs [82].

A new nucleation control method has been demonstrated with polymeric microgels through the adjustment of the microstructure, systematically varying the degree of microscopic confinement. It was found that the polymer microstructure significantly impacts the kinetics of nucleation, existing an optimal mesh value in which nucleation is dramatically improved, and which depends on the polymer-solute interactions $[83,84]$.

The application of gels in controlled techniques for crystal growth takes special importance, as it allows the broadening of the versatility of these techniques. In this framework, the use of gel in the sitting drop vapor diffusion method can be described; in this case, the surface tension between the crystal and the solution generates growth defects that are more sensitive to the instability of a convective regime, than to the convective regime itself. Therefore, a gel may be used in the sitting drop if the gelification time is short, as compared to the dehydration and concentration rate, since dehydration does not alter the gel's homogeneity. The use of gel even allows the feedback of a sitting drop with fresh material, since convection that would appear inevitable in the reload may be avoided [85]. An ulterior development is the gel acupuncture method, which was first used for the growth of lysozyme crystals [86] to avoid static growth of the protein inside the gel. Growth in the gel acupuncture method maintains the advantages of the use of gels, using a single diffusive pathway along a capillary pipette. The performance of gels was evaluated in terms of gel type, $\mathrm{pH}$, 
gelification time, pore size, and solubility, using thaumatin, lysozyme, and catalase to contrast the effect. The results showed an increase in crystal size and a decrease in the number of crystals [87].

Gels have been frequently used for controlling the morphological and polymorphical behavior of calcium carbonate. It has been reported that polyacrylamide gels yield considerable morphological differences [88]. Under these conditions, the formation of pre-nucleation clusters and a growth mechanism of co-planarity for a specific morphology has been observed [89].

Based on the information exposed so far, it is logical to propose using different types of acids that are compatible with gels. Polyacrylamide hydrogels with acrylic acid in a double diffusion array have been used. The presence of carboxylate in the gel's mesh facilitates the nucleation of multiple small vaterite and calcite crystals, which are temporarily stabilized, even if the gel's supersaturation is increased [90].

Gels can incorporate molecules that assist the formation of specific polymorphs, just as it happens in solution. Once again, the formation of calcium carbonate was studied, using a collagen matrix with L-aspartate polypeptides, and it was found that the selectivity for the calcium carbonate polymorph depends on the local supersaturation of the microenvironment where nucleation and crystal growth occur. As mentioned in the previous sections, the gel causes local nucleation to take place at high supersaturation, so it is possible to obtain metastable polymorphs such as vaterite and calcite. The specific orientations of the calcium carbonate polymorphs can be controlled either by a charged polypeptide with a beta structure, or by the structural organization of the triple helicoidal stretches of the collagen matrix. This results in the growth and assembly of crystals with specific shapes and sizes, by the molecular recognition of one specific crystal plane, or by the macromolecular control of the microenvironment.

Several recent studies have shown that acid macromolecules are responsible for the selective precipitation of the different calcium carbonate polymorphs in vitro. Poly-L-aspartate is capable of binding to the gel mesh, actively controlling the organization of crystal units; when the molecules of the gel orient themselves in the direction of a deformation, the average pore volume is reduced, increasing the range of stability for aragonite and vaterite, but reducing it for calcite.

In the gel, local supersaturation happens as a function of the negatively charged polypeptide, as well as of the volume of the pores where nucleation occurs. The reduction of the nucleation volume, due to uniaxial deformation, and the increase of concentration of the negatively charged polypeptides generate higher local supersaturations.

The strong electric field, caused by the increase in concentration and by the compactness of the spatial distribution of the negatively charged carboxylate groups, favors the interaction with the more positively charged crystalline plane (Figure 6). Vaterite has a greater tendency to interact with the two homocharged planes of calcium, (001) and (100), with a charge density close to 6.7 calcium ions per square nanometer, whereas calcite has a charge density of 4.5 Ca ions $/ \mathrm{nm}^{2}$ and aragonite 5 Ca ions $/ \mathrm{nm}^{2}$ (Figure 6) [12].

The presence of negatively charged amino acids stabilizes the highly charged planes of vaterite, favoring the formation of this polymorph.

The diffusion regime that is meant to be imposed with the use of gels can be accentuated by recurring to other methods capable of reducing convection. The use of a stationary magnetic field has been published. The effect of magnetic fields is related to the anisotropy due to the existence of alpha helices and peptide bonds. In a nuclear magnetic resonance (NMR) experiment, agarose and silica hydrogel were used; the gel was applied inside an NMR tube with the crystallization mixture consisting of agar, protein, and precipitating agent. Two magnets of 300 and $500 \mathrm{MHz}$, with 7 and $10 \mathrm{~T}$, respectively, were used. The results showed an improvement in the quality of the crystal when using a magnetic force greater than $7 \mathrm{~T}$, decreasing the mosaicity and the tilt angle. Also, it was observed that in high intensity magnetic fields, crystals align in its direction [91]. 


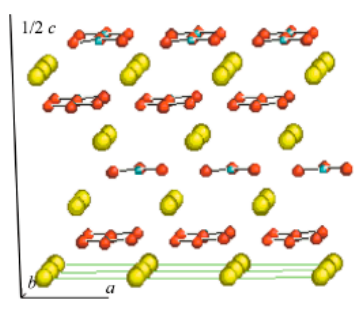

Calcite

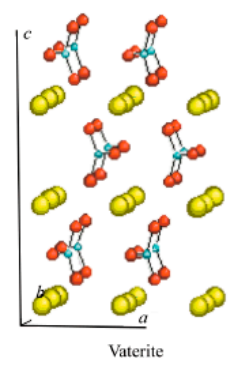

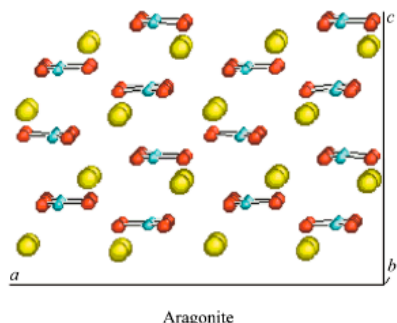

Charge density of calcium ions (ions per $\mathrm{nm}^{2}$ ) in different crystalline planes of calcium carbonate polymorphs

\begin{tabular}{lccc}
\hline & $(001)$ & $(012)$ & $(100)$ \\
\hline Calcite & 4.5 & 6.7 & \\
Aragonite & 5.0 & & \\
Vaterite & 6.7 & & 6.7 \\
\hline
\end{tabular}

Figure 6. Calcium carbonate polymorphs organization and charge [12]. With permit of the copyright (Copyright Clearance Center License 4635640148155).

A remarkable innovation is the advent of adjustable supramolecular gels. A supramolecular gel consists of small organic molecules that can assemble themselves in a continuous structure, with the same polymeric characteristics as a traditional gel. However, the difference lies in the interactions that allow the solid structure to remain stable; in supramolecular gels, these are intermolecular forces, particularly hydrophobic interactions, saline bonds, and transition metals coordination. As Figure 7 shows, a supramolecular gel may be detailed in terms of the dimension in which it is evaluated. At a molecular level, it is a system that interacts intermolecularly; however, when the number of molecules involved increases, the system aggregates in a similar and predictable manner, thus with a structure that is practically identical to a traditional gel [92].

(c')

$\left(d^{\prime}\right)$

$\left(e^{\prime}\right)$

(f)

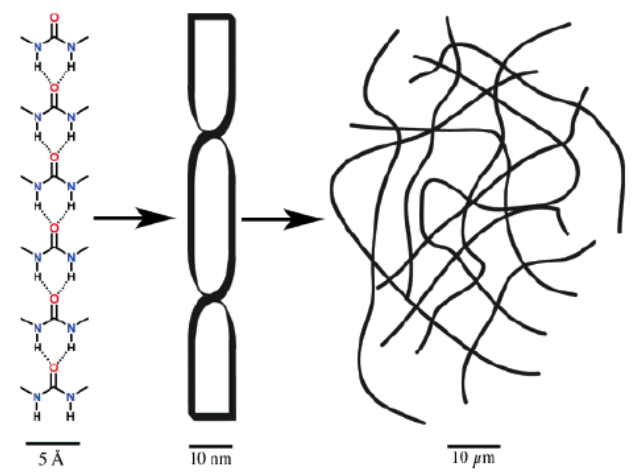

(a)
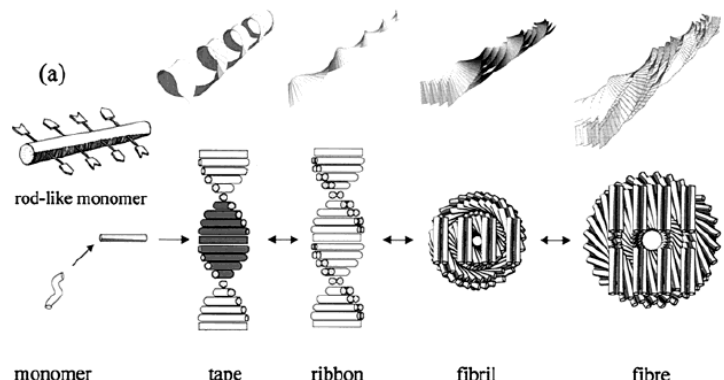

monomer

(c)

(d)

(d)

(e)

Figure 7. Structure of a supramolecular gel. Different structural levels are shown. Reprinted with permission from [92]. Copyright 2004 American Chemical Society.

Supramolecular gels of bis(urea) have been used as a medium for crystal growth of several molecules in the pharmaceutical industry, such as sparfloxacin, piroxicam, theophylline, caffeine, ibuprofen, acetaminophen, sulindac, and indomethacin. These gels allow the access of a limited range of solvents, in contrast with conventional aqueous gels such as agarose gels. In many cases, crystals were conveniently retrieved from the gel by dissolving the latter, supramolecularly initiated by an acetate anion. 
An advantage of low molecular weight gels is that due to their diverse nature, they can be used with almost any solvent, including organic solvents (Figure 8). Clear differences are observed in the crystal habit when the gel phase is compared to experiments performed in parallel in solution, including the polymorphic preference in the latter [93].
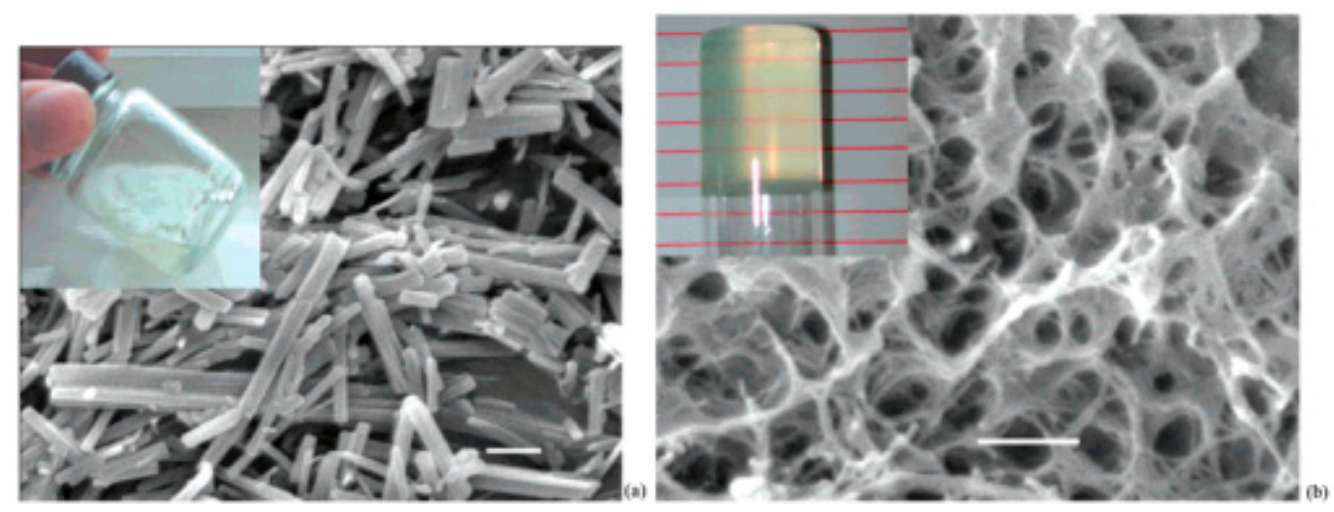

Figure 8. Micrograph of a low molecular gel. Reprinted with permission from [94]. (a) Separate fibers occurring in the $10 \mathrm{wt} \% \mathrm{~L}-\mathrm{DHL} / \mathrm{DIOP}$ system. It shows L-DHL needles short and thick fibers). This system gives rise to an opaque as shown in the picture on the left upper corner. The length of the bar: $1 \mu \mathrm{m}$. (b) Interconnected fiber networks in $10 \mathrm{wt} \% \mathrm{~L}-\mathrm{DHL} / \mathrm{DIOP}$ system after adding $0.004 \mathrm{wt} \%$ EVACP. It shows L-DHL nanocrystal fibers. This system gives rise to a clear and tough gel as shown in the picture on the right upper corner. The length of the bar: $1 \mu \mathrm{m}$. The acronyms L-DHL/DIOP stand for lanosta-8,24-dien-3 $\beta$-ol:24,25-dihydrolanosterol/di-isooctylphthalate; EVACP stands for ethylene/vinyl acetate copolymer. Copyright 2002 American Chemical Society.

A combination of strategies for nucleation control using a molecular template and supramolecular gels has been recently published. A precursor of olanzapine (a drug for the treatment of schizophrenia) known as ROY has been used as a model for this study. Seven different polymorphs have been found for ROY; hence, a polymorphic control is necessary. Conveniently, the colorfulness of these polymorphs facilitates their qualitative evaluation in situ. Figure 9 illustrates the structure of both the precursor and the monomer of the gel, and also the structures of bis(urea) that form the basic units of the supramolecular gel (1 and $\mathbf{2})$, which imitate the structure of the nitrobenzene ring present in the ROY structure. As a control test, these gels were also used without this ring in the fabrication of the supramolecular gel. In gels of 2 , with a ROY concentration of $100 \mathrm{mg} \cdot \mathrm{mL}^{-1}$, the metastable form of the structure was obtained almost every time, whereas the controls yielded only the stable form. To explain this result, a study of the conformational profile was performed through the formation of low energy structures in molecular mechanics, followed by the optimization of functionals of dispersion-corrected density corrected for the gel, and a calculation of the crystalline structure for the metastable ROY solid. It was found that the structure of ROY seems to be oriented by a stacking of the nitrobenzenurea section [95].

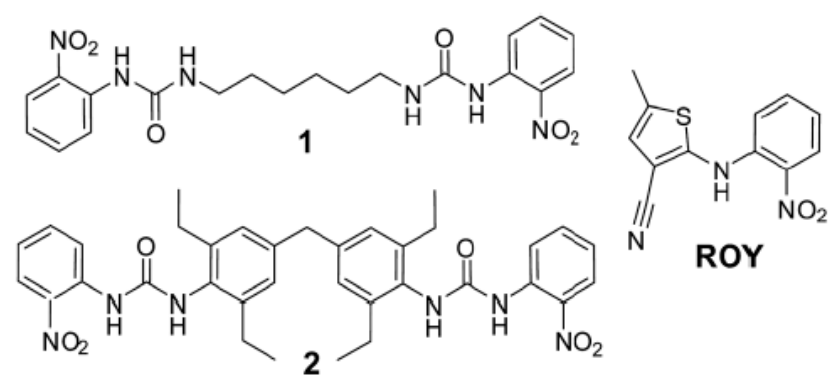

Figure 9. Structure of ROY and supramolecular gel monomers [95]. Reproduced by permission of The Royal Society of Chemistry (UK). 


\section{Protein Crystallization in Gels}

\subsection{Particular Characteristics of Protein Crystal Growth}

It is appropriate to consider proteins separately, given that their size and conformational versatility provide them with unique characteristics, even if they follow the same principles as other molecules when it comes to crystallization. In the case of human hemoglobin, for instance, there also exists a liquid-liquid separation for the formation of pre-nucleation clusters, even at different $\mathrm{pH}$ values, ionic strengths, hemoglobin concentrations, and at temperatures between 35 and $40^{\circ} \mathrm{C}$. Being evaluated in different proteins and conditions, it appears to be a general phenomenon [96].

The concept of cluster formation seems to introduce a non-classical nucleation mechanism. In the case of proteins, their interaction with other substances may lead to assisted morphologic or polymorphic controls, though it may even be directed by specific associations between proteins. As an example, bovine pancreas trypsin was used for crystallization in a membrane using ammonium sulfate as the precipitating agent. Crystals were obtained in a $24-48$ hours period in the static configuration, and in 4-7 days in the flow-driven configuration, optimizing the membrane surface and the flow velocity [97]. Furthermore, the combination of materials composed by membranes and hydrogels has been published; through a controlled chemical composition and nanostructure, it generates a heterogeneous support for hen eggshell lysozyme crystallization. Diverse morphological characteristics can take place as a result, as the kinetics of phase separation is being controlled in the gel layer on the membrane support [98].

The intrinsic associations of proteins may even orient the structure of the cluster. This has happened while evaluating four polymorphs of a hydrophobic helicoidal decapeptide; the associations of these structures are driven by the imperative need to minimize the surface area accessible to the solvent, through the formation of blocks which are subsequently settled by multiple hydrogen bonds in the head-tail region (Figure 10). This seems to indicate that polymorphism in protein structures may be driven by molecular association, and thus there are multiple nuclei with similar energy and packing patterns [15].
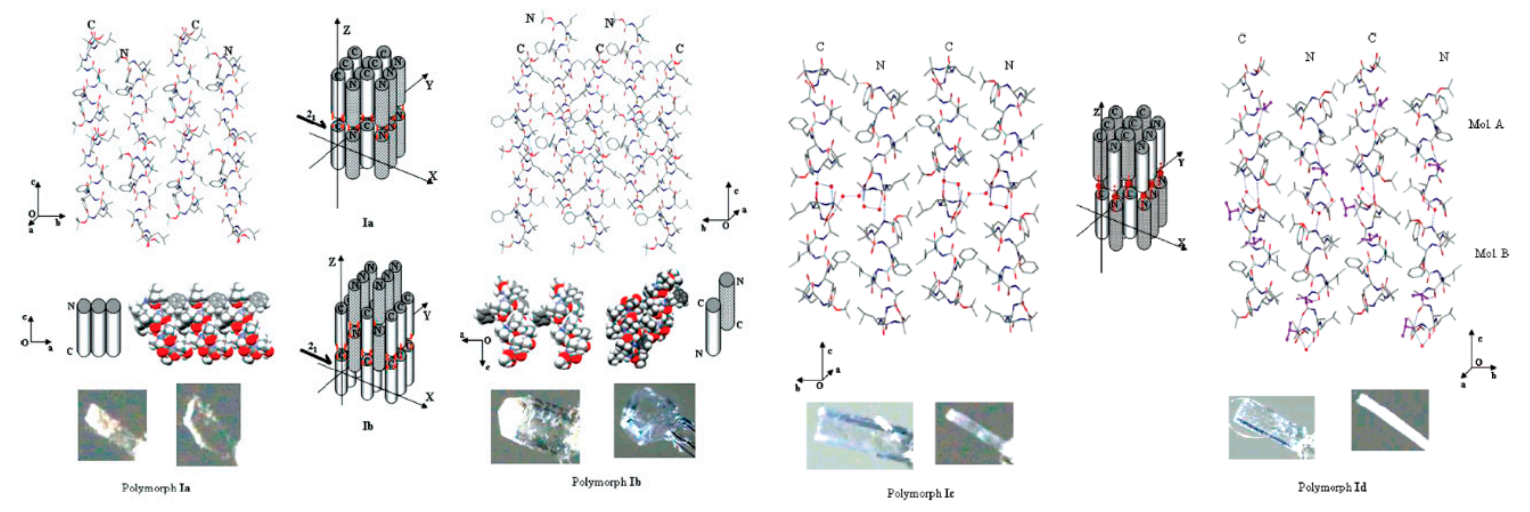

Figure 10. Display and packing of a decapeptide's polymorphs. Reprinted with permission from [15]. Copyright 2008 American Chemical Society (USA).

An in situ cryo-TEM study of glucose isomerase polymorphism further justifies this idea. Time-resolved transmission electron cryo-microscopy allows creation of an image of the formation of the protein crystals, and to describe at molecular resolution the nucleation pathways that lead to both crystal forms. The selection of the polymorph happens at the initial stages of structure formation, and it is based upon specific construction blocks for each spatial group (Figure 11a). In fact, the selection of the polymorph is proven to be possibly drivable through the mutagenesis of the direct site, by guiding the intermolecular bonds. In this case, the actual vision of the protein nucleation, in which a metastable dense liquid is a precursor of the crystalline state, is not observed. What is actually observed are 
the nucleation events driven by the orientation of the coupling of different sub-clusters that exhibit a certain degree of crystallinity themselves (Figure 11b) [16].
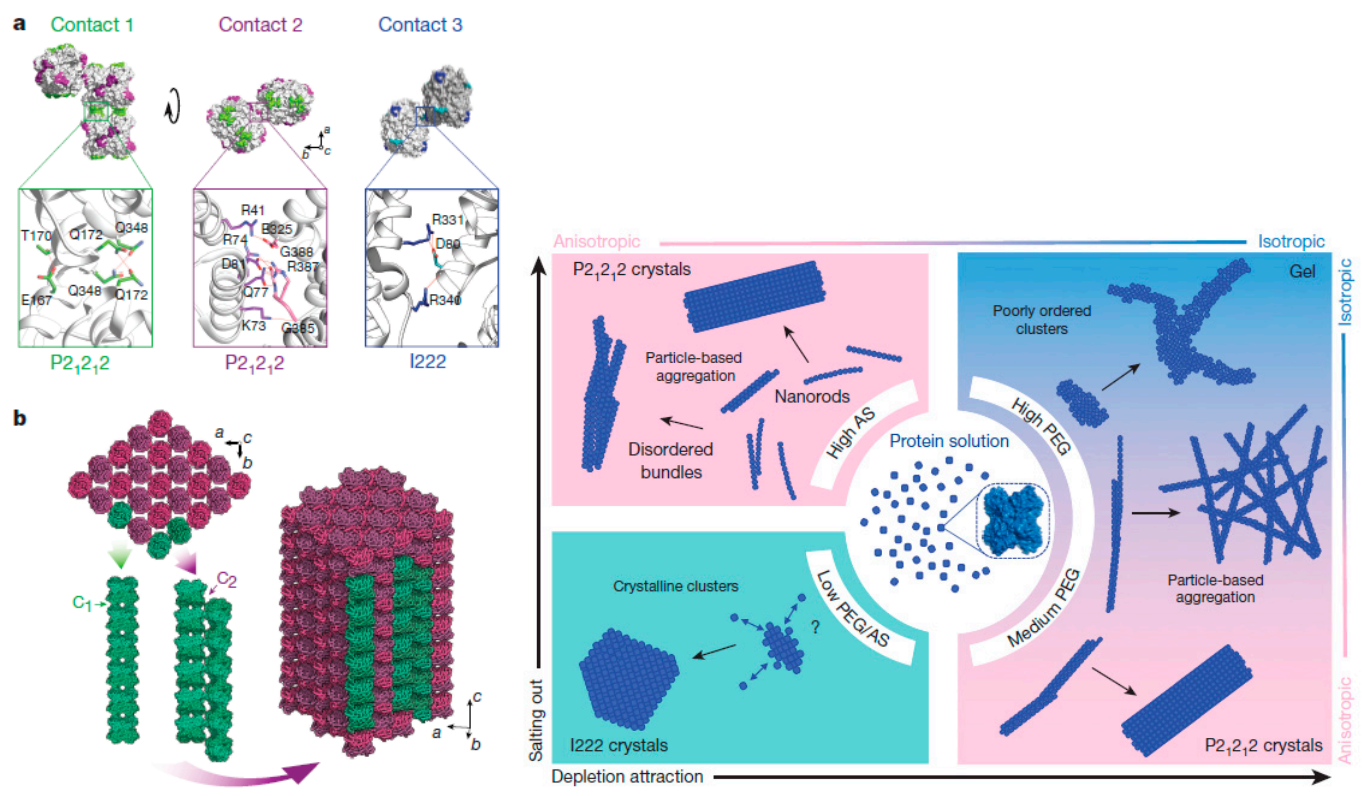

Figure 11. Effect of different contacts in the formation of specific glucose isomerase polymorphs [16]. With permit of the copyright (Copyright Clearence Center License 4635640920216).

A combination of a gel with a recognition molecule, using ionic liquids, has also been used for glucose isomerase. Crystals grow completely immersed in the hydrogel layer, probably by the specific interaction of proteins with the ionic liquids. This growth has shown to have an influence on space group and polymorphism [99].

\subsection{New Trends of Crystal Growth in Gels and the Use of Magnetic Fields: All-Inclusive Method}

Structural resolution of biomacromolecules, a fundamental step in the development of new pharmacological and biomedical strategies, can be made by X-ray crystallography, a powerful technique to determine efficiently three-dimensional structures [100]. Additional characterization may be made with NMR, small-angle X-ray scattering (SAXS), and increasingly, cryo-electron microscopy (cryo-EM). Still, to this day, X-ray crystallography keeps providing many a new solved high-resolution structure of proteins. While software for the resolution and refinement of diffraction data improves constantly, it remains an important requisite for X-ray crystallography to have a crystal comprising very pure and ordered protein molecules that will diffract the radiation into an adequate pattern for its resolution [101]. Several approaches have been tested to improve protein crystal quality, some of which involve modifying the physical environment where crystals nucleate and grow. Within these approaches, applying a magnetic field throughout crystal growth has proven to be successful, since crystals show greater quality in key quality indicators [102].

It has been reported that inhomogeneous magnetic fields reduce the gravitational forces of a solution through the action of a magnetic force, i.e., a magnetizing force is generated on the sample if a magnetic field is applied vertically. If this occurs opposite to the gravitational force, then the convection of the sample solution is diminished due to the reduction in the vertical acceleration [103]. Additionally, strong magnetic fields increase the viscosity of supersaturated solutions by reducing the convective transport phenomenon and thus modifying the diffusion phenomenon during biomacromolecules crystal nucleation and growth. A sufficient reduction of the convection could mimic microgravity conditions, therefore resulting in higher quality crystals [103-106]. 
In particular, NMR magnets have been used as a source of a static magnetic field, giving good results with control proteins such as lysozyme, among others. This technique is done by placing the protein samples in capillary pipettes inside the NMR glass tubes and leaving them in the magnetic field throughout the entire crystal growth process, to ensure a higher quality of the crystals $[103,106]$.

The crystal growth cell used for experiments in which the NMR magnet is applied, is based on the capillary batch method of crystal growth in agarose gels, as depicted in Figure 12, based on the same setup previously published in [103,107]. Chemical and physical gels provide an environment that differs in its viscosity and thus restricts mass transport to diffusion. Agarose is a physical gel that is practical for addition to crystallization solutions of biological macromolecules. Table 2 in [108] describes a protocol for the preparation of such assays, which has been slightly modified for the growth of protein crystals. Agarose gel stock solution of $0.6 \%(\mathrm{w} / \mathrm{v})$ of low melting point agarose (Tgel $=297-298 \mathrm{~K}$, Hampton Research Cod. HR8-092) is prepared by dissolving $0.1 \mathrm{~g}$ agarose in $10 \mathrm{ml}$ of water, heated at $363 \mathrm{~K}$, and then passed through a $0.22 \mu \mathrm{m}$ membrane filter. The agarose solution, mixed with precipitant solution, is left to cool down to a non-denaturing temperature for protein addition. For these experiments, crystal growth in gels under a magnetic field of 16.5 Tesla was recently combined with the application of pulses of radio frequency [109].

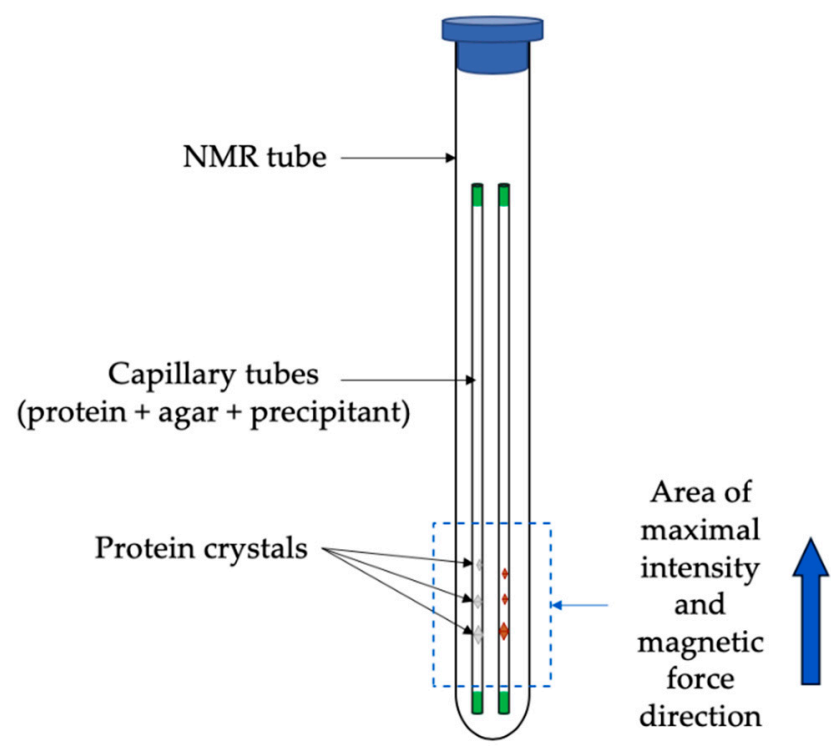

Figure 12. NMR tube setup for the capillary pipettes containing the protein solutions for crystal growth. This tube will be inserted into de magnet for the entirety of the experiment with the breathing pulses programming (described in the text below).

The batch crystallization conditions for the selected protein are needed in advance to apply this kind of methodology. Once sealed, the capillary pipettes should be introduced into an NMR glass tube ( $5 \mathrm{~mm}$ in diameter) and left for at least $68 \mathrm{~h}$ under the presence of a magnetic field of 16.5 Tesla (Brucker NMR Advance III HD $700 \mathrm{MHz}$ spectrometer) equipped with a $5 \mathrm{~mm}$ broadband probe head and a variable temperature unit (VTU). The designed pulse sequence for proton NMR acquisition is used to apply pulses of radio frequencies as those described in Figure 13. All experiments are performed at the temperature of $293 \mathrm{~K}$ controlled by a unit of the VTU of the NMR spectrometer or at the temperature of the crystallization of the selected protein. After finishing the experiment, the NMR tube is usually recovered from the magnet, and the capillary pipettes are carefully extracted from the NMR tube. All crystals are immediately mounted and flash-cooled for X-ray data collection. 


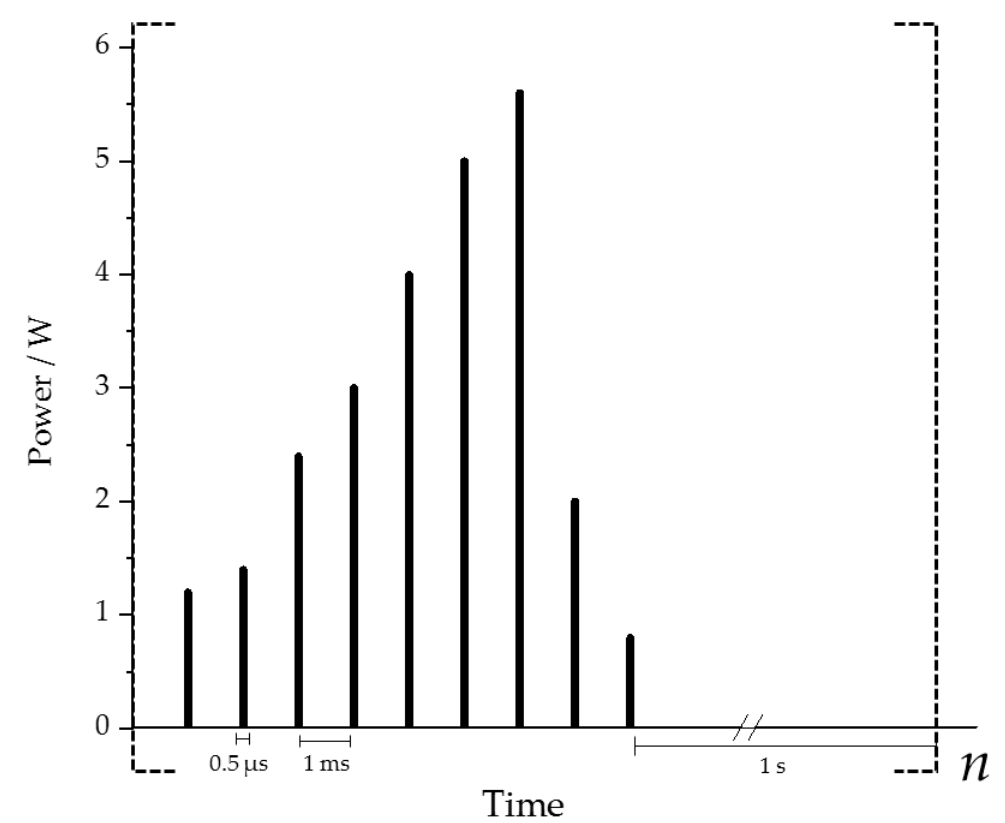

Figure 13. Breathing-like pattern programmed for the NMR pulse waves; $n=300,000$ cycles of repetition.

3.2.1. Case Studies Using Ferritin and Thaumatin Grown in Gels and under the Presence of a Strong Magnetic Field

For this experiment, two model proteins were studied: ferritin, a protein rich in alpha helices, and thaumatin, with a lesser content of alpha helices (rich in beta sheets). It is well known that the magnetic force is much more effective when having high contents of alpha helices, because the anisotropy of the diamagnetic susceptibility is very high. These proteins, ferritin and thaumatin, were grown under a particular NMR pulse pattern described as breathing pulse waves (NMR-bp). These pulses, as their name suggests, are composed by a cycle that starts with a gradual increase in the magnetic force immediately followed by a less gradual decrease, as if a person's breathing behavior were being recorded (Figure 13).

Ferritin was first described as a hepatic iron-storage protein, which crystallizes in high-salt conditions and has a crystallographic symmetry pertaining to a cubic space group [110,111], which is consistent with our findings. Meanwhile, thaumatin was initially proposed as a non-toxic, non-caloric sweetener isolated from fruit of West African Thaumatococcus daniellii [112,113]. Crystallographic resolution from thaumatin agarose gel crystallization has a symmetry pertaining to a tetragonal space group [114], which is consistent with our findings.

\subsubsection{Crystallization Conditions and Experimental Setup}

Ferritin from horse spleen and thaumatin from T. daniellii were obtained already purified from Sigma (St. Louis, Missouri, USA), and set for crystallization. The final crystallization conditions for ferritin were $0.8 \mathrm{M}\left(\mathrm{NH}_{4}\right)_{2} \mathrm{SO}_{4}$ prepared in $100 \mathrm{mM}$ Tris- $\mathrm{HCl} \mathrm{pH} \mathrm{7.5,} \mathrm{and} 60 \mathrm{mM} \mathrm{CdSO}_{4}$; the protein concentration was of $75 \mathrm{mg} \cdot \mathrm{ml}^{-1}$. The final crystallization conditions for thaumatin were Na K tartrate $10 \%(\mathrm{w} / \mathrm{v})$ and a protein concentration of $40 \mathrm{mg} \cdot \mathrm{ml}^{-1}$. For each protein, the precipitating solution was mixed with gel solution, and finally mixed with the protein solution at the same proportion (1:1:1). Once sealed, the capillary pipettes with protein controls (i.e., no breathing pulse waves) were left to crystallize at $294 \mathrm{~K}$. Concomitantly, capillary pipettes for each protein were introduced into an NMR glass tube and left for $6 \mathrm{~d}, 23 \mathrm{~h}$ and $39 \mathrm{~m}$ under breathing pulse waves programmed to complete 300,000 cycles, to promote protein nucleation. Once the experiment was finished, the NMR tube was taken out of the magnet to extract the capillary tubes from it. Crystals that have indeed grown should be harvested, starting by cutting the capillary pipettes at both sides. For this we used a commercial 
cutting stone (Hampton Research Cod. HR4-334), and afterwards we applied mild air pressure to expel the crystals into a cryoprotectant solution for flash-cooling. Both the NMR-bp grown crystals and the control crystals were transported to synchrotron facilities for X-ray diffraction data collection and crystal structure resolution.

\subsubsection{Results and Discussions}

Nucleation is the first step in the growth of biomacromolecules crystals, which begins when the crystallization solution reaches the supersaturation state [101]. This step is crucial in the formation of homogeneous sizeable crystals that do not present topological imperfections and polycrystalline growth. Crystals of both thaumatin and ferritin grown under control conditions possess such imperfections (Figure 14a,c) which in turn complicates the harvesting for X-ray diffraction data collection. The effect of the NMR field on crystal orientation has been reported [103], but, to our knowledge, never with this pattern of breathing pulses. The crystals grown under the all-inclusive method using NMR breathing pulse waves have a clear improvement in size, homogeneity, and orientation (Figure 14b,d). The neat arrangement of these crystals then allows for easy harvesting, flash-cooling, and mounting for X-ray data collection, albeit size and homogeneity in the crystal do not always account for good diffraction data for solving the 3D structure by X-ray crystallographic methods [114-118]. The most important part for this obtainment of high-quality single crystals is the growth under diffusion-control transport in gels. These gel-growth methods have been recently reviewed [119-121].
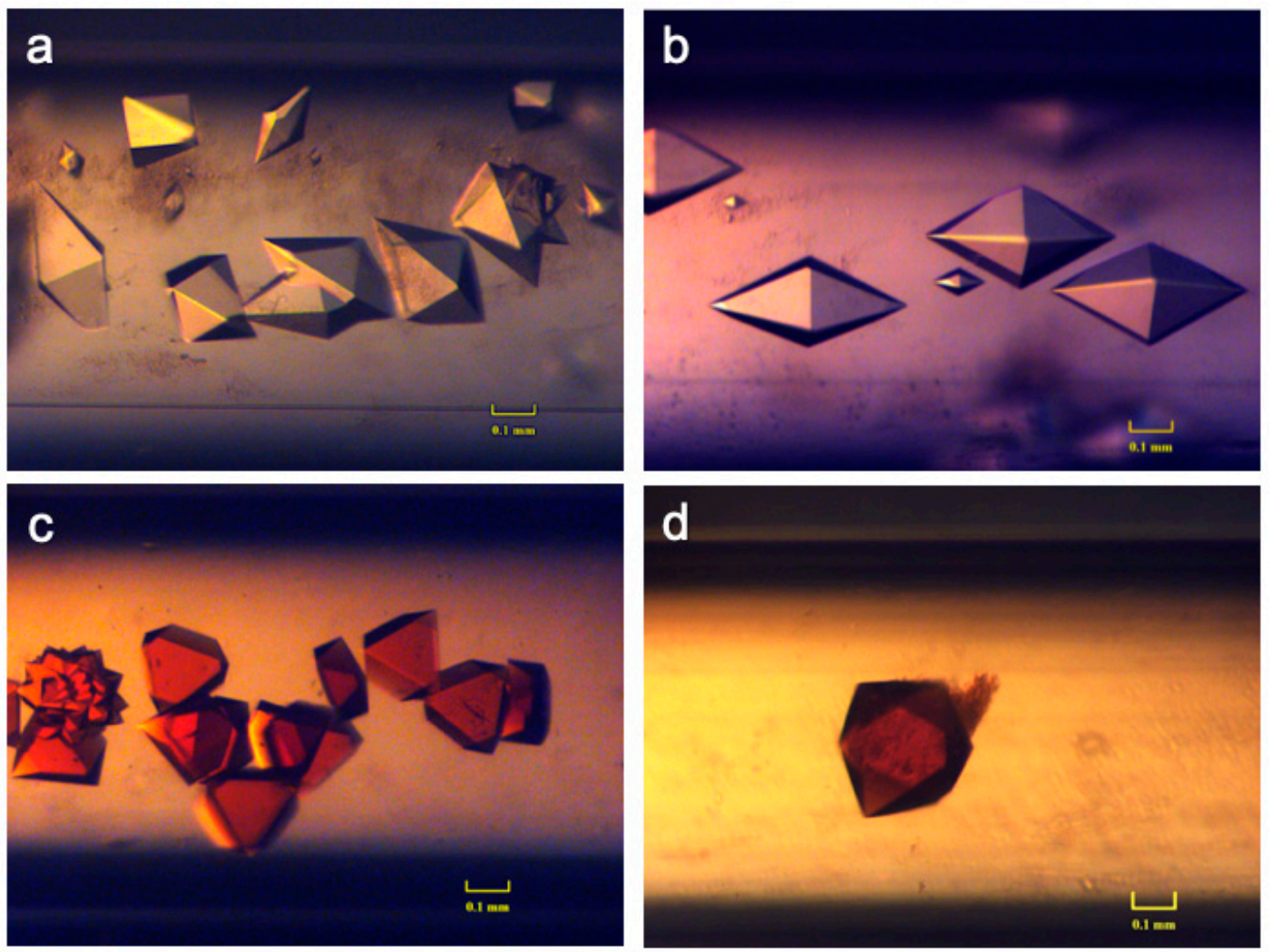

Figure 14. Crystals of thaumatin and ferritin were grown in agarose capillary pipettes; $(\mathbf{a}, \mathbf{c})$ are the control proteins, showing multiple topological imperfections as well as polycrystalline growth; (b,d) are the NMR-bp grown crystals, which have an improved size, homogeneity, and orientation.

We can obtain two main advantages when applying this methodology for growing crystals; the first is as follows: when applying this all-inclusive method, the higher the content of alpha helices in the protein is, the higher the crystal improvement in terms of crystal quality will be. All crystals grown 
in gels (in general) will show a good crystal quality, so these controls will be excellent to substantially improve que crystal quality when combining gels with magnetic fields. The second advantage is that a smaller number of bigger crystals can be obtained with a homogeneous crystal size, with (in the best case) higher crystal quality compared to the control crystals. The experiment with the best crystallization conditions, taking care of all parameters (fixing the temperature, using well-known batch crystallization conditions, considering the induction time for nucleation, etc.) allowed us to get for ferritin gel-NMR-bp diffraction data up to $1.28 \AA$. For thaumatin, gel-NMR-bp crystals diffracted up to $1 \AA$ at the synchrotron facility (ELETTRA located in Trieste Italy).

The availability of small focused beams at third generation light source facilities further allow characterization of crystals regarding quality and homogeneity. Most macromolecular beam lines today allow probing of sample diffraction resolution limits by performing the translation of the sample through the beam in fixed steps as it gets rotated in small angular steps. These so-called raster scans provide information on the homogeneity of diffraction quality but also represent a map of the mosaic domains of the crystals. With beam sizes of the order of 1 micron, these maps are related to the "tiles" that make up the samples. Figure 15 shows a comparison of raster scans from thaumatin crystals grown with and without exposure to a magnetic field (FMX beam line NSLS-II synchrotron). Despite the relatively large pixel size of the detector used, 75 microns for the Eiger $16 \mathrm{M}$, these scans can be viewed as the "poor men's" X-ray diffraction topograph.
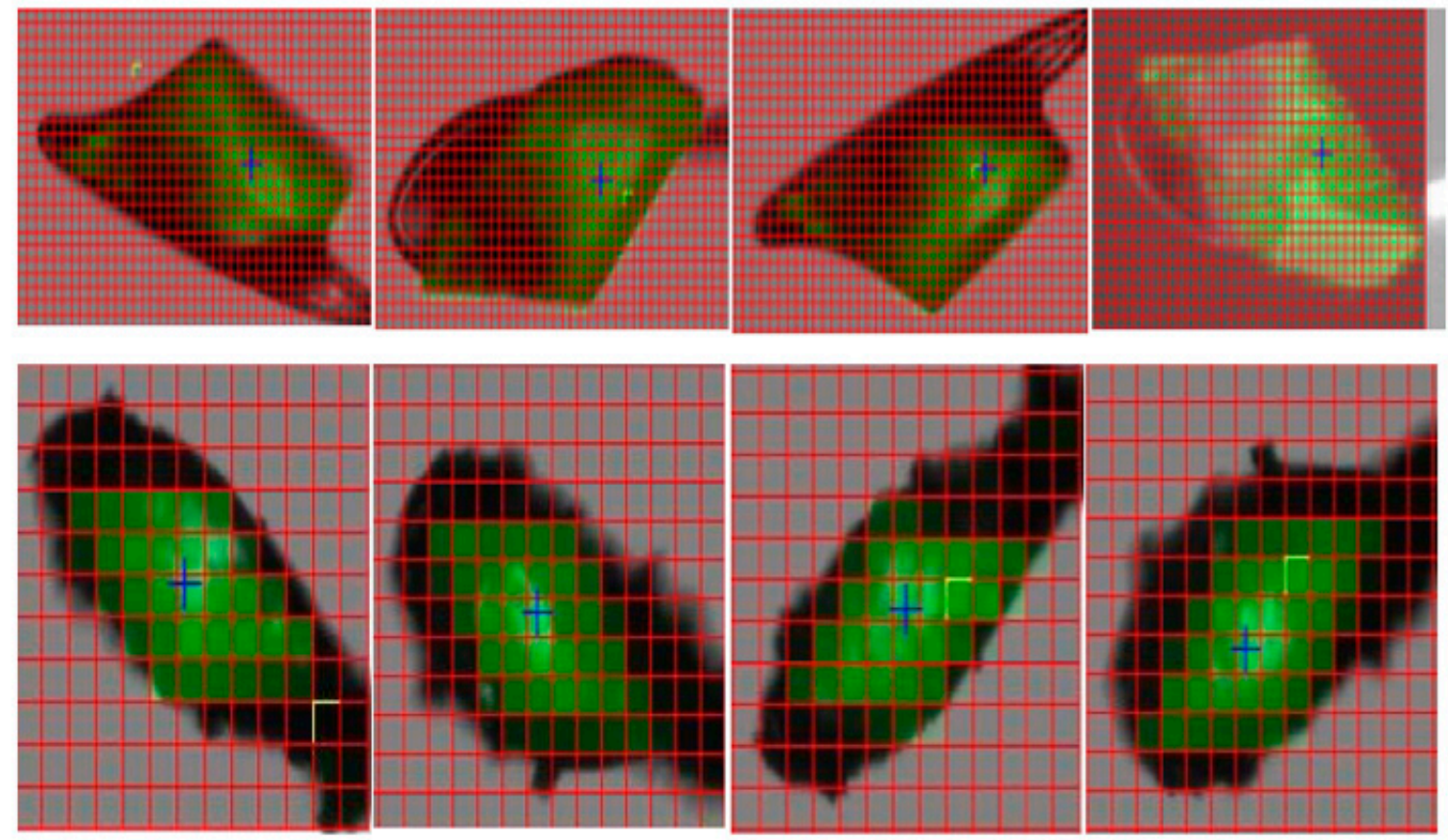

Figure 15. "Raster scans" from thaumatin crystals grown in agarose capillary pipettes; top panel crystals grown as control, bottom panel NMR-bp grown crystals; images shown from left to right were taken in 90 degrees steps. Control crystals show a large area without diffraction, dark area, while NMR-bp grown crystals show uniform illumination.

\section{Concluding Remarks}

The results presented in this review are an example of the future experiments that can be performed when using crystal growth in gels, where the beauty of crystals in terms of control size and homogeneity, as well as high crystal quality, can be easily achieved. In the gel-method, one of the most stable polymorphs is usually obtained. The most promising proteins to be tested for these types of experiments described in the last part of this review are the membrane proteins, which are rich in alpha helices. Perhaps full macromolecular complexes can be also crystallized in the near future 
by combining all the possibilities that crystal growth in gels, magnetic influence on crystal growth, and the control of nucleation are offering from the very beginning, when setting up the crystallization experiments. This short review has shown the most important mechanisms used to obtain high-quality single crystals in gels. The effect on the nucleation and the advantages provided by the gel-growth method combined with electromagnetic fields opens a world of possibilities to grow crystals of a variety of biological macromolecules with high-resolution crystal quality for crystallographic research.

Author Contributions: Conceptualization, A.M. and O.V.-G.; methodology, O.V.-G., C.C.-E., A.F.-I.; investigation, O.V.-G., C.C.-E., A.F.-I., N.E.-E., V.S.; M.C.-C.; R.A.-E. writing-original draft preparation, O.V.-G.; writing-review and editing, A.M., O.V.-G., C.C.-E.; supervision, A.M.; project administration, A.M.; R.A.-E.; funding acquisition, A.M.; R.A.-E.

Funding: There is no external funding.

Acknowledgments: All the authors acknowledge to the ELETTRA Synchrotron in Trieste (Italy) for X-ray diffraction and data collection of thaumatin and ferritin crystals as well as to the National Synchrotron Light Source of the Brookhaven National Laboratory in Upton New York for the preliminary analysis of model protein crystals. This review and part of the results shown in the last part were supported by DGAPA-UNAM project PAPIIT No. IG200218. The FMX beam line at the NSLS-II is supported by the National Institute of Health, National Institute of General Medical Sciences (NIGMS) through P41-GM111244, and by the DOE Office of Biological and Environmental Research BER (KP1605010). The National Synchrotron Light Source II facility is supported by the U. S. Department of Energy, DE-SC0012704 (KC0401040). The authors acknowledge to Babak Andi and Wuxian Shi for their assistance and support.

Conflicts of Interest: The authors declare no conflict of interest.

\section{References}

1. Burger, A. The Relevance of Polymorphism. Pharm. Int. 1983, 4, 186.

2. Lee, E.H. A Practical Guide to Pharmaceutical Polymorph Screening \& Selection. Asian J. Pharm. Sci. 2014, 9, 163-175.

3. Hernández-Paredes, J.; Olvera-Tapia, A.L.; Arenas-García, J.I.; Höpfl, H.; Morales-Rojas, H.; Herrera-Ruiz, D.; Gonzaga-Morales, A.I.; Rodríguez-Fragoso, L. On Molecular Complexes Derived from Amino Acids and Nicotinamides in Combination with Boronic Acids. CrystEngComm 2015, 17, 5166-5186. [CrossRef]

4. Long, S.; Zhou, P.; Theiss, K.L.; Siegler, M.A.; Li, T. Solid-State Identity of 2-Hydroxynicotinic Acid and Its Polymorphism. CrystEngComm 2015, 17, 5195-5205. [CrossRef]

5. Tenorio Clavijo, J.C.; Guimarães, F.F.; Ellena, J.; Martins, F.T. Isostructurality and the Conformational Role of the $2^{\prime}, 3^{\prime}$-Moieties in the Diversity of Lamivudine Crystal Forms Probed in Halide Salts. CrystEngComm 2015, 17, 5187-5194. [CrossRef]

6. Abramov, Y.A. Virtual Hydrate Screening and Coformer Selection for Improved Relative Humidity Stability. CrystEngComm 2015, 17, 5216-5224. [CrossRef]

7. Upadhyay, P.P.; Bond, A.D. Crystallization and Disorder of the Polytypic A1 and A2 Polymorphs of Piroxicam. CrystEngComm 2015, 17, 5266-5272. [CrossRef]

8. Maddileti, D.; Nangia, A. Polymorphism in Anti-Hyperammonemic Agent N-Carbamoyl-1-Glutamic Acid. CrystEngComm 2015, 17, 5252-5265. [CrossRef]

9. Hean, D.; Gelbrich, T.; Griesser, U.J.; Michael, J.P.; Lemmerer, A. Structural Insights into the Hexamorphic System of an Isoniazid Derivative. CrystEngComm 2015, 17, 5143-5153. [CrossRef]

10. Horstman, E.M.; Bertke, J.A.; Kim, E.H.; Gonzalez, L.C.; Zhang, G.G.Z.; Gong, Y.; Kenis, P.J.A. Crystallization and Characterization of Cocrystals of Piroxicam and 2,5-Dihydroxybenzoic Acid. CrystEngComm 2015, 17, 5299-5306. [CrossRef]

11. Cruz-Cabeza, A.J.; Reutzel-Edens, S.M.; Bernstein, J. Facts and Fictions about Polymorphism. Chem. Soc. Rev. 2015, 44, 8619-8635. [CrossRef] [PubMed]

12. Falini, G.; Fermani, S.; Gazzano, M.; Ripamonti, A. Polymorphism and Architectural Crystal Assembly of Calcium Carbonate in Biologically Inspired Polymeric Matrices. J. Chem. Soc. Dalt. Trans. 2000, 3983-3987. [CrossRef]

13. Tohse, H.; Saruwatari, K.; Kogure, T.; Nagasawa, H.; Takagi, Y. Control of Polymorphism and Morphology of Calcium Carbonate Crystals by a Matrix Protein Aggregate in Fish Otoliths. Cryst. Growth Des. 2009, 9, 4897-4901. [CrossRef] 
14. Fratzl, P.; Aizenberg, J.; Addadi, L.; Falini, G.; Reggi, M.; Fermani, S.; Sparla, F.; Goffredo, S.; Dubinsky, Z.; Levi, O.; et al. Control of Aragonite Deposition in Colonial Corals by Intra-Skeletal Macromolecules. J. Struct. Biol. 2013, 183, 226-238.

15. Vasudev, P.G.; Shamala, N.; Balaram, P. Nucleation, Growth, and Form in Crystals of Peptide Helices. J. Phys. Chem. B 2008, 112, 1308-1314. [CrossRef] [PubMed]

16. Van Driessche, A.E.S.; Van Gerven, N.; Bomans, P.H.H.; Joosten, R.R.M.; Friedrich, H.; Gil-Carton, D.; Sommerdijk, N.A.J.M.; Sleutel, M. Molecular Nucleation Mechanisms and Control Strategies for Crystal Polymorph Selection. Nature 2018, 556, 89-94. [CrossRef]

17. McCrone, W.C. Polymorphism. Phys. Chem. Org. Solid State 1965, 2, 726-767.

18. Saridakis, E.; Dierks, K.; Moreno, A.; Dieckmann, M.W.M.; Chayen, N.E. Separating Nucleation and Growth in Protein Crystallization Using Dynamic Light Scattering. Acta Crystallogr. Sect. D Biol. Crystallogr. 2002, 58, 1597-1600. [CrossRef]

19. Gibbs, J.W. Equilibrium of Heterogenous Substances. Am. J. Sci. 1878, 16, 441-458. [CrossRef]

20. Frenkel, J. A General Theory of Heterophase Fluctuations and Pretransition Phenomena. J. Chem. Phys. 1939, 7, 538-547. [CrossRef]

21. Gutiérrez-Quezada, A.E.; Arreguín-Espinosa, R.; Moreno, A. Protein Crystal Growth Methods. In Springer Handbook of Crystal Growth; Dhanaraj, G., Byrappa, K., Prasad, V., Dudley, M., Eds.; Springer: Berlin/Heidelberg, Germany, 2010; pp. 1583-1605.

22. Sand, K.K.; Rodriguez-Blanco, J.D.; Makovicky, E.; Benning, L.G.; Stipp, S.L.S. Crystallization of $\mathrm{CaCO}_{3}$ in Water-Alcohol Mixtures: Spherulitic Growth, Polymorph Stabilization, and Morphology Change. Cryst. Growth Des. 2012, 12, 842-853. [CrossRef]

23. Chen, S.F.; Yu, S.H.; Hang, J.; Li, F.; Liu, Y. Polymorph Discrimination of $\mathrm{CaCO}_{3}$ Mineral in an Ethanol/Water Solution: Formation of Complex Vaterite Superstructures and Aragonite Rods. Chem. Mater. 2006, 18, 115-122. [CrossRef]

24. Nicolaï, B.; Espeau, P.; Céolin, R.; Perrin, M.A.; Zaske, L.; Giovannini, J.; Leveiller, F. Polymorph Formation from Solvate Desolvation: Spironolactone Forms i and II from the Spironolactone-Ethanol Solvate. J. Therm. Anal. Calorim. 2007, 90, 337-339. [CrossRef]

25. Kulkarni, S.A.; Meekes, H.; Ter Horst, J.H. Polymorphism Control through a Single Nucleation Event. Cryst. Growth Des. 2014, 14, 1493-1499. [CrossRef]

26. Garg, R.K.; Sarkar, D. Polymorphism Control of P-Aminobenzoic Acid by Isothermal Anti-Solvent Crystallization. J. Cryst. Growth 2016, 454, 180-185. [CrossRef]

27. Lai, T.T.C.; Cornevin, J.; Ferguson, S.; Li, N.; Trout, B.L.; Myerson, A.S. Control of Polymorphism in Continuous Crystallization via Mixed Suspension Mixed Product Removal Systems Cascade Design. Cryst. Growth Des. 2015, 15, 3374-3382. [CrossRef]

28. Padrela, L.; Zeglinski, J.; Ryan, K.M. Insight into the Role of Additives in Controlling Polymorphic Outcome: A CO $\mathrm{CO}_{2}$-Antisolvent Crystallization Process of Carbamazepine. Cryst. Growth Des. 2017, 17, 4544-4553. [CrossRef]

29. Hatakka, H.; Alatalo, H.; Louhi-Kultanen, M.; Lassila, I.; Hæggström, E. Closed-Loop Control of Reactive Crystallization Part II: Polymorphism Control of L-Glutamic Acid by Sonocrystallization and Seeding. Chem. Eng. Technol. 2010, 33, 751-756. [CrossRef]

30. Stolar, T.; Lukin, S.; Tireli, M.; Sović, I.; Karadeniz, B.; Kereković, I.; Matijašić, G.; Gretić, M.; Katančić, Z.; Dejanović, I.; et al. Control of Pharmaceutical Cocrystal Polymorphism on Various Scales by Mechanochemistry: Transfer from the Laboratory Batch to the Large-Scale Extrusion Processing. ACS Sustain. Chem. Eng. 2019, 7, 7102-7110. [CrossRef]

31. Zbačnik, M.; Nogalo, I.; Cinčić, D.; Kaitner, B. Polymorphism Control in the Mechanochemical and Solution-Based Synthesis of a Thermochromic Schiff Base. CrystEngComm 2015, 17, 7870-7877. [CrossRef]

32. Cinčić, D.; Brekalo, I.; Kaitner, B. Solvent-Free Polymorphism Control in a Covalent Mechanochemical Reaction. Cryst. Growth Des. 2012, 12, 44-48. [CrossRef]

33. Freund, F.; Williams, S.C.; Johnson, R.D.; Coldea, R.; Gegenwart, P.; Jesche, A. Single Crystal Growth from Separated Educts and Its Application to Lithium Transition-Metal Oxides. Sci. Rep. 2016, 6, 1-19. [CrossRef] [PubMed]

34. Chong, K.Y.; Chia, C.H.; Zakaria, S. Polymorphs Calcium Carbonate on Temperature Reaction. AIP Conf. Proc. 2014, 1614, 52-56. 
35. Rungsimanon, T.; Yuyama, K.I.; Sugiyama, T.; Masuhara, H.; Tohnai, N.; Miyata, M. Control of Crystal Polymorph of Glycine by Photon Pressure of a Focused Continuous Wave Near-Infrared Laser Beam. J. Phys. Chem. Lett. 2010, 1, 599-603. [CrossRef]

36. Miura, K.; Fujiwara, K.; Tsukazaki, A. Growth Control of Corundum-Derivative $\mathrm{MnSnO}_{3}$ Thin Films by Pulsed-Laser Deposition. AIP Adv. 2019, 9. [CrossRef]

37. Wang, H.; Wang, Z.; Liu, L.; Gong, X.; Wang, M. Alumina Hydrate Polymorphism Control in Al-Water Reaction Crystallization by Seeding to Change the Metastable Zone Width. Cryst. Growth Des. 2016, 16, 1056-1062. [CrossRef]

38. Little, L.J.; King, A.A.K.; Sear, R.P.; Keddie, J.L. Controlling the Crystal Polymorph by Exploiting the Time Dependence of Nucleation Rates. J. Chem. Phys. 2017, 147. [CrossRef]

39. Violante, A.; Huang, P.M. Formation Mechanism of Aluminum Hydroxide Polymorphs. Clays Clay Miner. 1993, 41, 590-597. [CrossRef]

40. Ogino, T.; Suzuki, T.; Sawada, K. The Formation and Transformation Mechanism of Calcium Carbonate in Water. Geochim. Cosmochim. Acta 1987, 51, 2757-2767. [CrossRef]

41. McNaught, A.D.; Blackwell, W.; IUPAC. Compendium of Chemical Terminology; Scientific Publications: Oxford, UK, 1997. [CrossRef]

42. Lifshitz, I.M.; Slyozov, V. The Kinetics of Precipitation from Supersaturated Solid Solutions. J. Phys. Chem. Solids 1961, 19, 35-50. [CrossRef]

43. Mizuno, K.; Mura, T.; Uchida, S. Control of Polymorphisms and Functions in All-Inorganic Ionic Crystals Based on Polyaluminum Hydroxide and Polyoxometalates. Cryst. Growth Des. 2016, 16, 4968-4974. [CrossRef]

44. Navrotsky, A. Energetic Clues to Pathways to Biomineralization: Precursors, Clusters, and Nanoparticles. Proc. Natl. Acad. Sci. USA 2004, 101, 12096-12101. [CrossRef] [PubMed]

45. Lee, S.; Wi, H.S.; Jo, W.; Cho, Y.C.; Lee, H.H.; Jeong, S.-Y.; Kim, Y.-I.; Lee, G.W. Multiple Pathways of Crystal Nucleation in an Extremely Supersaturated Aqueous Potassium Dihydrogen Phosphate (KDP) Solution Droplet. Proc. Natl. Acad. Sci. USA 2016, 113, 13618-13623. [CrossRef] [PubMed]

46. Desgranges, C.; Delhommelle, J. Molecular Mechanism for the Cross-Nucleation between Polymorphs. J. Am. Chem. Soc. 2006, 128, 10368-10369. [CrossRef] [PubMed]

47. Desgranges, C.; Delhommelle, J. Insights into the Molecular Mechanism Underlying Polymorph Selection. J. Am. Chem. Soc. 2006, 128, 15104-15105. [CrossRef] [PubMed]

48. Nguyen, A.H.; Molinero, V. Cross-Nucleation between Clathrate Hydrate Polymorphs: Assessing the Role of Stability, Growth Rate, and Structure Matching. J. Chem. Phys. 2014, 140. [CrossRef] [PubMed]

49. Bonn, D.; Shahidzadeh, N. Multistep Crystallization Processes: How Not to Make Perfect Single Crystals. Proc. Natl. Acad. Sci. USA 2016, 113, 13551-13553. [CrossRef]

50. Vekilov, P.G. Two-Step Mechanism for the Nucleation of Crystals from Solution. J. Cryst. Growth 2005, 275, 65-76. [CrossRef]

51. Gebauer, D.; Völkel, A.; Cölfen, H. Stable Prenucleation Calcium Carbonate Clusters. Science 2008, 322, 1819-1822. [CrossRef]

52. Li, K.; Wu, S.; Xu, S.; Du, S.; Zhao, K.; Lin, L.; Yang, P.; Yu, B.; Hou, B.; Gong, J. Oiling out and Polymorphism Control of Pyraclostrobin in Cooling Crystallization. Ind. Eng. Chem. Res. 2016, 55, 11631-11637. [CrossRef]

53. Muschol, M.; Rosenberger, F. Liquid-Liquid Phase Separation in Supersaturated Lysozyme Solutions and Associated Precipitate Formation/Crystallization. J. Chem. Phys. 1997, 107, 1953-1962. [CrossRef]

54. Mattei, A.; Li, T. Polymorph Formation and Nucleation Mechanism of Tolfenamic Acid in Solution: An Investigation of Pre-Nucleation Solute Association. Pharm. Res. 2012, 29, 460-470. [CrossRef] [PubMed]

55. Wang, J.; Liu, K.; Xing, R.; Yan, X. Peptide Self-Assembly: Thermodynamics and Kinetics. Chem. Soc. Rev. 2016, 45, 5589-5604. [CrossRef] [PubMed]

56. Capetti, E.; Ferretti, A.M.; Santo, V.D.; Ponti, A. Surfactant-Controlled Composition and Crystal Structure of Manganese(II) Sulfide Nanocrystals Prepared by Solvothermal Synthesis. Beilstein J. Nanotechnol. 2015, 6, 2319-2329. [CrossRef] [PubMed]

57. Kwon, O.P.; Kwon, S.J.; Jazbinsek, M.; Choubey, A.; Losio, P.A.; Gramlich, V.; Günter, P. Morphology and Polymorphism Control of Organic Polyene Crystals by Tailor-Made Auxiliaries. Cryst. Growth Des. 2006, 6, 2327-2332. [CrossRef] 
58. Ruiz-Arellano, R.R.; Medrano, F.J.; Moreno, A.; Romero, A. Structure of Struthiocalcin-1, an Intramineral Protein from Struthio Camelus Eggshell, in Two Crystal Forms. Acta Crystallogr. Sect. D Biol. Crystallogr. 2015, 71, 809-818. [CrossRef]

59. Reyes-Grajeda, J.P.; Marín-García, L.; Stojanoff, V.; Moreno, A. Purification, Crystallization and Preliminary X-Ray Analysis of Struthiocalcin 1 from Ostrich (Struthio Camelus) Eggshell. Acta Crystallogr. Sect. F Struct. Biol. Cryst. Commun. 2007, 63, 987-989. [CrossRef]

60. Marín-García, L.; Frontana-Uribe, B.A.; Reyes-Grajeda, J.P.; Stojanoff, V.; Serrano-Posada, H.J.; Moreno, A. Chemical Recognition of Carbonate Anions by Proteins Involved in Biomineralization Processes and Their Influence on Calcite Crystal Growth. Cryst. Growth Des. 2008, 8, 1340-1345. [CrossRef]

61. Falini, G.; Albeck, S.; Weiner, S.; Addadi, L. Control of Aragonite or Calcite Polymorphism by Mollusk Shell Macromolecules. Science 1996, 271, 67-69. [CrossRef]

62. Zou, Z.; Bertinetti, L.; Politi, Y.; Fratzl, P.; Habraken, W.J.E.M. Control of Polymorph Selection in Amorphous Calcium Carbonate Crystallization by Poly(Aspartic Acid): Two Different Mechanisms. Small 2017, 13, 1603100. [CrossRef]

63. Mandal, D.; Yoon, S.; Kim, K.J. Prepration of Silver Nanoparticles Doped Pvdf: Formation of Piezoelectric Polymorph. In Proceedings of the 18th International Conference on Composite Materials (ICCM), Jeju Island, Korea, 21-26 August 2011; pp. 1-4.

64. Kim, K.; Centrone, A.; Hatton, T.A.; Myerson, A.S. Polymorphism Control of Nanosized Glycine Crystals on Engineered Surfaces. CrystEngComm 2011, 13, 1127-1131. [CrossRef]

65. Rusa, C.C.; Wei, M.; Bullions, T.A.; Rusa, M.; Gomez, M.A.; Porbeni, F.E.; Wang, X.; Shin, I.D.; Balik, C.M.; White, J.L.; et al. Controlling the Polymorphic Behaviors of Semicrystalline Polymers with Cyclodextrins. Cryst. Growth Des. 2004, 4, 1431-1441. [CrossRef]

66. Tulli, L.G.; Moridi, N.; Wang, W.; Helttunen, K.; Neuburger, M.; Vaknin, D.; Meier, W.; Shahgaldian, P. Polymorphism Control of an Active Pharmaceutical Ingredient beneath Calixarene-Based Langmuir Monolayers. Chem. Commun. 2014, 50, 3938-3940. [CrossRef] [PubMed]

67. Chang, M.H.; Chou, W.Y.; Lee, Y.C.; Cheng, H.L.; Chung, H.Y.; Chang, C.C.; Chiu, C.Y.; Ho, T.Y. Polymorphic Transformation Induced by Nanoimprinted Technology in Pentacene-Film Early-Stage Growth. Appl. Phys. Lett. 2010, 97. [CrossRef]

68. Khademhosseini, A.; Demirci, U. Gels Handbook: Fundamentals, Properties and Applications; World Scientific Pub Co Inc.: Toh Tuck, Singapore, 2016.

69. Aizawa, M.; Suzuki, S. Properties of Water in Macromoleular Gels. III. Dilatometric Studies of the Properties of Water in Macromolecular Gels. Bull. Chem. Soc. Jpn. 2006, 44, 2967-2971. [CrossRef]

70. Aizawa, M.; Suzuki, S.; Suzuki, T.; Toyama, H. The Properties of Water in Macromolecular Gels. VI. The Relationship between the Rheological Properties and the States of Water in Macromolecular Gels. Bull. Chem. Soc. Jpn. 2006, 46, 1638-1640. [CrossRef]

71. Aizawa, M.; Mizuguchi, J.; Suzuki, S.; Hayashi, S.; Suzuki, T.; Mitomo, N.; Toyama, H. Properties of Water in Macromolecular Gels. IV. Proton Magnetic Resonance Studies of Water Iu Macromolecular Gels. Bull. Chem. Soc. Jpn. 2006, 45, 3031-3034. [CrossRef]

72. Rogovina, L.Z.; Vasil'ev, V.G.; Braudo, E.E. Definition of the Concept of Polymer Gel. Polym. Sci. Ser. C 2008, 50, 85-92. [CrossRef]

73. Tuvikene, R.; Truus, K.; Kollist, A.; Volobujeva, O.; Mellikov, E.; Pehk, T. Gel-Forming Structures and Stages of Red Algal Galactans of Different Sulfation Levels. J. Appl. Phycol. 2008, 527-535. [CrossRef]

74. Blank, Z.; Reimschuessel, A.C. Structural Studies of Organic Gels by SEM. J. Mater. Sci. 1974, 9, $1815-1822$. [CrossRef]

75. Robert, M.C.; Lefaucheux, F. Crystal Growth in Gels: Principle and Applications. J. Cryst. Growth 1988, 90, 358-367. [CrossRef]

76. García-Ruiz, J.M. The Uses of Crystal Growth in Gels and Other Diffusing-Reacting Systems. Key Eng. Mater. 2009, 58, 87-106. [CrossRef]

77. Henisch, H.K.; García-Ruiz, J.M. Crystal Growth in Gels and Liesegang Ring Formation I. Diffusion Relationships. J. Cryst. Growth 1986, 75, 195-200. [CrossRef]

78. Henisch, H.K.; García-Ruiz, J.M. Crystal Growth in Gels and Liesegang Ring Formation. II. Crystallization Criteria and Successive Precipitation. J. Cryst. Growth 1986, 75, 203-211. [CrossRef]

79. Liesegang, R.E. Chemische Reaktionen in Gallerten; Naturwiss Wschr: Leipzig, Germany, 1924. (In German) 
80. Henisch, H.K.; Dennis, J.; Hanoka, J.I. Crystal Growth in Gels. J. Phys. Chem. Solids 1965, 26, 1-9. [CrossRef]

81. McCaurEyl, J.; Roy, R. Controlled Nucleation and Crystal Growth of Various $\mathrm{CaCO}_{3}$ Phases by the Silica Gel Technique. Am. Mineral. 1974, 59, 947-963.

82. Franke, W.A.; Mehran, N.-A. Crystal Growth in Gels at Elevated Pressures: The Upper Limit of Temperature for Metastable Formation of Aragonite. Cryst. Res. Technol. 1992, 27, 295-299. [CrossRef]

83. Diao, Y.; Helgeson, M.E.; Myerson, A.S.; Hatton, T.A.; Doyle, P.S.; Trout, B.L. Controlled Nucleation from Solution Using Polymer Microgels Ying. J. Am. Chem. Soc. 2011, 132, 3756-3759. [CrossRef] [PubMed]

84. Myerson, A.S.; Woldeyes, M.A.; Doyle, P.S.; Whaley, K.E.; Hatton, T.A.; Helgeson, M.E.; Diao, Y.; Trout, B.L. Gel-Induced Selective Crystallization of Polymorphs. J. Am. Chem. Soc. 2011, 134, 673-684.

85. Bernard, Y.; Degoy, S.; Lefaucheux, F.; Robert, M.C. A Gel-Mediated Feeding Technique for Protein Crystal Growth from Hanging Drops. Acta Crystallogr. Sect. D Biol. Crystallogr. 1994, 50, 504-507. [CrossRef]

86. García-Ruiz, J.M.; Moreno, A. Investigations on Protein Crystal Growth by the Gel Acupuncture Method. Acta Crystallogr. Sect. D Biol. Crystallogr. 1994, 50, 484-490. [CrossRef] [PubMed]

87. Moreno, A.; Juárez-Martínez, G.; Hernández-Pérez, T.; Batina, N.; Mundo, M.; McPherson, A. Physical and Chemical Properties of Gels Application to Protein Nucleation Control in the Gel Acupuncture Technique. J. Cryst. Growth 1999, 205, 375-381. [CrossRef]

88. Grassmann, O.; Müller, G.; Löbmann, P. Organic-Inorganic Hybrid Structure of Calcite Crystalline Assemblies Grown in a Gelatin Hydrogel Matrix: Relevance to Biomineralization. Chem. Mater. 2002, 14, 4530-4535. [CrossRef]

89. Grassmann, O.; Neder, R.B.; Putnis, A.; Löbmann, P. Biomimetic Control of Crystal Assembly by Growth in an Organic Hydrogel Network. Am. Mineral. 2003, 88, 647-652. [CrossRef]

90. Grassmann, O.; Löbmann, P. Biomimetic Nucleation and Growth of CaCO3 in Hydrogels Incorporating Carboxylate Groups. Biomaterials 2004, 25, 277-282. [CrossRef]

91. Moreno, A.; Quiroz-García, B.; Yokaichiya, F.; Stojanoff, V.; Rudolph, P. Protein Crystal Growth in Gels and Stationary Magnetic Fields. Cryst. Res. Technol. 2007, 42, 231-236. [CrossRef]

92. Estroff, L.A.; Hamilton, A.D. Water Gelation by Small Organic Molecules. Chem. Rev. 2004, 104, $1201-1218$. [CrossRef]

93. Foster, J.A.; Piepenbrock, M.O.M.; Lloyd, G.O.; Clarke, N.; Howard, J.A.K.; Steed, J.W. Anion-Switchable Supramolecular Gels for Controlling Pharmaceutical Crystal Growth. Nat. Chem. 2010, 2, 1037-1043. [CrossRef]

94. Liu, X.Y.; Sawant, P.D.; Tan, W.B.; Noor, I.B.M.; Pramesti, C.; Chen, B.H. Creating New Supramolecular Materials by Architecture of Three-Dimensional Nanocrystal Fiber Networks. J. Am. Chem. Soc. 2002, 124, 15055-15063. [CrossRef]

95. Foster, J.A.; Damodaran, K.K.; Maurin, A.; Day, G.M.; Thompson, H.P.G.; Cameron, G.J.; Bernal, J.C.; Steed, J.W. Pharmaceutical Polymorph Control in a Drug-Mimetic Supramolecular Gel. Chem. Sci. 2016, 8 , 78-84. [CrossRef]

96. Galkin, O.; Chen, K.; Nagel, R.L.; Hirsch, R.E.; Vekilov, P.G. Liquid-Liquid Separation in Solutions of Normal and Sickle Cell Hemoglobin. Proc. Natl. Acad. Sci. USA 2002, 99, 8479-8483. [CrossRef] [PubMed]

97. Di Profio, G.; Curcio, E.; Drioli, E. Trypsin Crystallization by Membrane-Based Techniques. J. Struct. Biol. 2005, 150, 41-49. [CrossRef] [PubMed]

98. Di Profio, G.; Polino, M.; Nicoletta, F.P.; Belviso, B.D.; Caliandro, R.; Fontananova, E.; De Filpo, G.; Curcio, E.; Drioli, E. Tailored Hydrogel Membranes for Efficient Protein Crystallization. Adv. Funct. Mater. 2014, 24, 1582-1590. [CrossRef]

99. Belviso, B.D.; Caliandro, R.; Salehi, S.M.; Di Profio, G.; Caliandro, R. Protein Crystallization in Ionic-Liquid Hydrogel Composite Membranes. Crystals 2019, 9, 253. [CrossRef]

100. Pareja-Rivera, C.; Cuéllar-Cruz, M.; Esturau-Escofet, N.; Demitri, N.; Polentarutti, M.; Stojanoff, V.; Moreno, A. Recent advances in the understanding of the influence of electric and magnetic fields on protein crystal growth. Cryst. Growth Des. 2017, 17, 135-145. [CrossRef]

101. Messerschmidt, A. X-Ray Crystallography of Biomacromolecules; Wiley-VCH Verlag GmbH \& Co.: Weinheim, Germany, 2007.

102. Yan, E.; Zhang, C.-Y.; He, J.; Yin, D.-C. An overview of hardware for protein crystallization in a magnetic field. Int. J. Mol. Sci. 2016, 17, 1906. [CrossRef] [PubMed] 
103. Ataka, M.; Wakayama, N.-C. Effects of a magnetic field and magnetization force on protein crystal growth. Why does a magnet improve the quality of some crystals? Acta. Crystallogr. 2002, D58, 1708-1710. [CrossRef]

104. Sazaki, G. Crystal quality enhancement by magnetic fields. Prog. Biophys. Mol. Biol. 2009, 101, 45-55. [CrossRef]

105. Surade, S.; Ochi, T.; Nietlispach, D.; Chirgadze, D.; Moreno, A. Investigations into protein crystallization in the presence of a strong magnetic field. Cryst. Growth Des. 2010, 10, 691-699. [CrossRef]

106. Yin, D.-C. Protein crystallization in a magnetic field. Progress in Crystal Growth and Characterization of Materials. Prog. Cryst. Growth Charact. Mater. 2015, 61, 1-26. [CrossRef]

107. Gil-Alvaradejo, G.; Ruiz-Arellano, R.R.; Owen, C.; Rodríguez-Romero, A.; Rudiño-Piñera, E.; Antwi, M.K.; Stojanoff, V.; Moreno, A. Novel protein crystal growth electrochemical cell for applications in X-ray diffraction and atomic force microscopy. Cryst. Growth Des. 2011, 11, 3917-3922. [CrossRef]

108. Lorber, B.; Sauter, C.; Théobald-Dietrich, A.; Moreno, A.; Schellenberger, P.; Robert, M.-C.; Capelle, B.; Sanglier, S.; Potier, N.; Giegé, R. Crystal growth of proteins, nucleic acids, and viruses in gels. Prog. Biophys. Mol. Biol. 2009, 101, 13-25. [CrossRef] [PubMed]

109. Rodríguez-Romero, A.; Esturau-Escofet, N.; Pareja-Rivera, C.; Moreno, A. Crystal Growth of High-Quality Protein Crystals under the Presence of an Alternant Electric Field in Pulse-Wave Mode, and a Strong Magnetic Field with Radio Frequency Pulses Characterized by X-ray Diffraction. Crystals 2017, 7, 179. [CrossRef]

110. Harrison, P.M. The structure of apoferritin: molecular size, shape and symmetry from x-ray data. J. Mol. Biol. 1963, 6, 404-422. [CrossRef]

111. Granick, S.; Hahn, P.F. Ferritin VIII—speed and uptake of iron by liver and its conversion to ferritin iron. J. Biol. Chem. 1994, 155, 661-669.

112. Van Der Wel, H.; Loeve, K. Isolation and characterization of thaumatin I and II, the sweet-tasting proteins from Thaumatococcus daniellii Benth. Eur. J. Biochem. 1972, 31, 221-225. [PubMed]

113. Most, B.H.; Summerfield, R.J.; Boxall, M. Tropical plants with sweetening properties physiological and agronomic problems of protected cropping 2. Tha uma tococcus daniellii. Econ. Bot. 1978, 32, 321-335. [CrossRef]

114. Lorber, B.; Sauter, C.; Robert, M.C.; Capelle, B.; Giegé, R. Crystallization within agarose gel in microgravity improves the quality of thaumatin crystals. Acta Crystallogr. 1999, 55, 1491-1494. [CrossRef]

115. Wlodawer, A.; Minor, W.; Dauter, Z.; Jaskolski, M. Protein crystallography for non-crystallographers, or how to get the best (but not more) from published macromolecular structures. FEBS J. 2008, 275, 1-21. [CrossRef]

116. Sanishvili, R.; Nagarajan, V.; Yoder, D.; Becker, M.; Xu, S.H.; Corcoran, S.; Akey, D.L.; Smith, J.L.; Fischetti, R.F. A $7 \mu$ mini-beam improves diffraction data from small or imperfect crystals of macromolecules. Acta Crystallogr. 2008, D64, 425-435.

117. Diederichs, K.; Karplus, P.A. Improved R-factors for diffraction data analysis in macromolecular crystallography. Nat. Struct. Biol. 1997, 4, 269-275. [CrossRef] [PubMed]

118. Adams, P.D.; Afonine, P.V.; Bunkóczi, G.; Chen, V.B.; Davis, I.W.; Echols, N.; Headd, J.J.; Hung, L.W.; Kapral, G.J.; Grosse-Kunstleve, R.W.; et al. PHENIX: A comprehensive Python-based system for macromolecular structure solution. Acta Crystallogr. 2010, 66, 213-221. [CrossRef] [PubMed]

119. Moreno, A.; Mendoza, M.E. Crystallization in Gels. In Handbook of Crystal Growth, 2nd ed.; Rudolph, P., Nishinaga, T., Eds.; Elsevier: Amsterdam, The Netherlands, 2015; Volume II, pp. 1277-1315.

120. Gavira, J.A. Current trends in protein crystallization. Arch. Biochem. Biophys. 2016, 602, 3-11. [CrossRef] [PubMed]

121. Moreno, A.; Rosales-Hoz, M. Crystal growth of inorganic, organic, and biological macromolecules in gels. Prog. Crystal Growth Charact. Mater. 2017, 3, 63-71. [CrossRef]

(C) 2019 by the authors. Licensee MDPI, Basel, Switzerland. This article is an open access article distributed under the terms and conditions of the Creative Commons Attribution (CC BY) license (http://creativecommons.org/licenses/by/4.0/). 